\title{
Fácies e superfícies de descontinuidade da barreira regressiva holocênica paranaense
}

\author{
Florença Nunes BISI' ${ }^{1}$ Rodolfo José ANGULO² \& Maria Cristina de SOUZA² \\ 1 Programa de Pós-graduação em Geologia, Universidade Federal do Paraná. BR-277, s/n, Centro \\ Politécnico, Jardim das Américas, CEP 81531-970, Curitiba, PR, Brasil (florencabisi@gmail.com). \\ 2 Laboratório de Estudos Costeiros, Departamento de Geologia, Universidade Federal do Paraná \\ (angulo@ufpr.br, cristinasouza@ufpr.br).
}

\begin{abstract}
Resumo. A barreira regressiva holocênica paranaense foi formada quando o nível relativo do mar era superior ao atual e é um dos sistemas deposicionais que formam a planície costeira paranaense. O objetivo deste artigo é demonstrar a correlação entre as superfícies de descontinuidade existentes na barreira com as suas fácies sedimentares e associações de fácies. Os afloramentos foram expostos em uma cava de extração de areia nas proximidades de Praia de Leste, litoral do estado do Paraná. Foram realizadas a caracterização e interpretação das fácies, associações de fácies e superfícies de descontinuidade a partir do levantamento e descrição de 5 seções geológicas. A barreira é constituída principalmente por areia quartzosa predominantemente muito fina a fina que pode conter alta concentração de minerais pesados e detritos vegetais na forma de estratificações cruzadas tipo swaley e hummocky. Foram identificadas 13 fácies correspondentes às associações de fácies praia subaérea-intermaré, face litorânea superior e face litorânea média. Superfícies de $1^{a}, 2^{a}$ e $3^{a}$ ordem foram identificadas. As superfícies de $3^{a}$ ordem foram identificadas nas três associações de fácies e foram relacionadas a elementos arquitetônicos da barreira, denominados: depósitos de face praial, de barras submersas e de delta de maré vazante.
\end{abstract}

Palavras-chave. Holoceno, arquitetura deposicional, análise de fácies, Quaternário costeiro

\begin{abstract}
FACIES AND BOUNDING SUFACES OS PARANÁ'S HOLOCENE REGRESSIVE BARRIER. The Holocene regressive barrier of Paraná was formed when the relative sea level was higher than present and is one of the depositional systems that form the coastal plain of Paraná. This work aims to demonstrate the correlation between the barrier bounding surfaces with their sedimentary facies and facies associations. The outcrops were exposed by excavations next Praia de Leste, coast of the state of Paraná. The characterization and interpretation of facies, facies associations and bounding surfaces were performed from the description of 5 geological sections. The barrier is composed of very fine to fine quartz sand which may contain hight concentrate of heavy minerals and plant debris in the form of swaley and hummocky cross stratification. There were identified 13 facies corresponding to the facies associations foreshore, upper shoreface and middle shoreface. Surfaces of 1st, 2nd and 3rd order were identified. The 3rd order surfaces were identified in the three facies associations and were related to architectural elements of the barrier, called: beach face, bars and ebb-tidal delta deposits.
\end{abstract}

Keywords. Holocene, depositional architecture, facies analysis, coastal Quaternary 


\section{Introdução}

A planície costeira paranaense é composta por dois sistemas de barreiras, um formado no Pleistoceno tardio e o outro no Holoceno (Martin et al., 1988). Anteriormente à formação dos depósitos mais antigos, cerca de 120.000 anos atrás, o nível do mar teria alcançado níveis em torno de $8,0 \mathrm{~m} \pm 2,0 \mathrm{~m}$ acima do atual (Martin et al., 1988). Posteriormente, o nível do mar atingiu um máximo de até $3,5 \mathrm{~m}$ acima do atual, entre 7.000 e 5.000 anos, durante o Holoceno (Angulo \& Lessa, 1997; Angulo et al., 2006). O último nível máximo atingido teria permanecido relativamente estável até cerca de 3.500 anos, quando as taxas de queda do nível do mar voltaram a aumentar e a progradação costeira deu origem ao sistema de barreiras holocênicas (Angulo et al., 2009). A formação da barreira regressiva holocênica paranaense teria ocorrido em ambiente costeiro comparável ao análogo atual; esta configuração caracteriza a formação da barreira em ambiente de média a alta energia de ondas sob influência de eventos de alta energia, associados à passagem de frentes frias (Souza, 2005; Souza et al., 2012). Os trabalhos existentes para a região sobre fácies e associação de fácies (e.g. Lessa et al., 2000; Souza et al., 2012) não deram ênfase às relações laterais entre as fácies nem às superfícies de descontinuidade. Sabe-se que tais estudos podem contribuir para a interpretação dos processos sedimentares durante a formação da barreira; assim, o objetivo deste artigo é identificar as relações laterais das fácies e associações de fácies e correlacioná-las com as superfícies de descontinuidade, para identificar os processos sedimentares e às condições ambientais existentes durante a formação da barreira, assim como elucidar elementos de sua arquitetura deposicional.

O termo "fácies" é definido como uma porção de depósito sedimentar caracterizada por uma combinação particular de estruturas sedimentares e biológicas que concedem um aspecto diferente aos depósitos sedimentares adjacentes acima, abaixo ou lateralmente; e sua caracterização é realizada em afloramentos e/ ou testemunhos com base em seus atributos genéticos, tais quais: granulometria, grau de seleção, estruturas físicas, conteúdo fossilífero e composição mineralógica (Dalrymple, 2010). As fácies definidas descritivamente em campo ou em testemunho podem, inicialmente, não sugerir um ambiente particular; a chave para a interpretação é analisar as fácies em conjunto e no contexto; assim, obtêm-se informações importantes que as fácies, quando consideradas individualmente, podem não oferecer (Dalrymple, 2010). Portanto, o conceito de "associação de fácies" vem da necessidade de combinação de fácies próximas e relacionadas entre si (Walker, 1992).

\section{2 Área, materiais e métodos}

\subsection{Localização da área}

O litoral paranaense é caracterizado por largas planícies costeiras e amplos complexos estuarinos (Angulo et al., 2009) (Fig. 1). As praias têm extensão de aproximadamente 126 km e são classificadas em três tipos: oceânicas, oceânicas sob influência das desembocaduras estuarinas e estuarinas (Angulo, 1993; Angulo \& Araújo, 1996). As praias são constituídas por areia fina a média, bem selecionada, e compostas, principalmente, por quartzo, fragmentos carbonáticos e minerais pesados (Angulo, 2004). Do ponto de vista morfodinâmico, são classificadas como praias intermediárias, com inclinações entre $1^{\circ}$ e $5^{\circ}$ e ao menos duas barras longitudinais na zona de arrebentação (Short, 1999). Quadros et al. (2007) descreveram a ocorrência da primeira barra de arrebentação a uma profundidade de 1,5 m de lâmina de água. A variação da energia das ondas incidentes causa alterações significativas no perfil da praia ao longo do tempo (Quadros, 2002). As ondas incidentes no litoral do Paraná, de leste e de sul, possuem período máximo de aproximadamente $16 \mathrm{~s}$ e altura sazonal máxima de 4,0 a 6,4 m (Pianca et al., 2010). As ondas de maior energia ocorrem com maior frequência durante os meses referentes ao outono e inverno e estão relacionadas à passagem de frentes frias (Pianca et al., 2010); estas podem gerar marés meteorológicas de 0,6 até 0,8 m acima do nível de maré previsto (astronômica) (Angulo, 1992; Marone \& Camargo, 1995). Nestas condições, as 
ondas são provenientes de SSE/SE e possuem característica não linear de propagação, o que implica maior poder energético de ressuspensão e transporte de sedimentos (Marone et al., 1997).

Para atender ao objetivo proposto, foram descritas cinco seções em um trecho da barreira holocênica paranaense (Fig. 1E), onde ocorrem afloramentos expostos pelo rebaixamento artificial do lençol freático em uma cava de extração de areia, em áreas com o mínimo de alteração. As seções denominadas 1, 2, 3, 4 e 5 se localizam nas coordenadas UTM/22S 750536 / 7154727; UTM/22S 750579 / 7154990; UTM/22S 750526 / 7155010; UTM/22S 750541 / 7155027 e UTM/22S 750538 / 7155025, respectivamente.

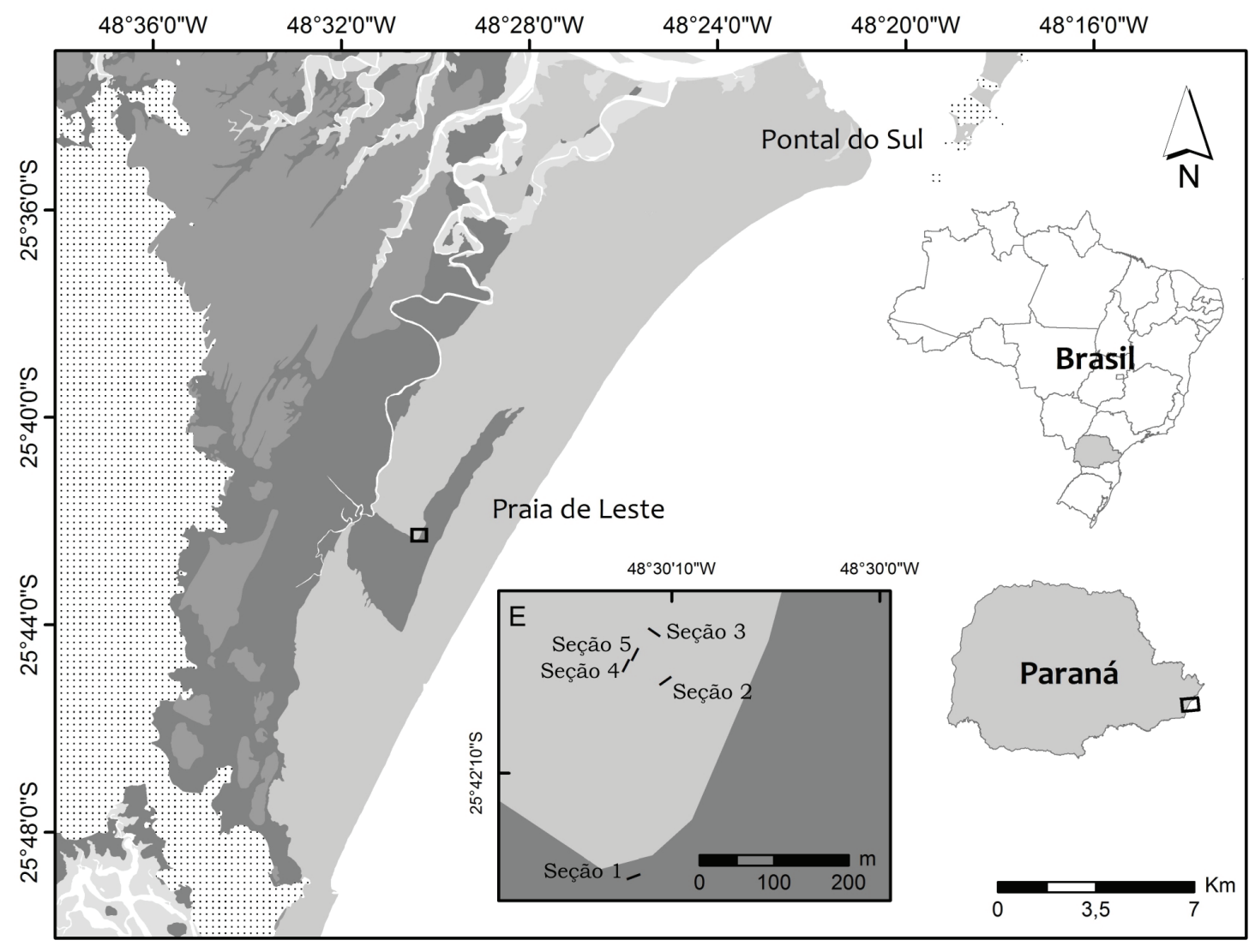
A)
B)
C)
D)

Figura 1. Mapa de localização. A) Barreira pleistocênica; B) Barreira holocênica; C) Depósitos paleoestuarinos; D) Outras unidades; E) Localização das seções geológicas.

Figure 1. Location map. A) Pleistocene barrier; B) Holocene barrier; C) Paleo-estuarine sediments; D) Other units; E) Location of the geological sections.

\subsection{Materiais e métodos}

As fácies foram classificadas de acordo com o trabalho de Souza et al. (2012), que descreveram a mesma barreira em área próxima, localizada a aproximadamente $200 \mathrm{~m}$ a nordeste. Estes autores utilizaram e adaptaram o sistema de códigos de fácies proposto por Miall (1978, 1996).

As direções de mergulho foram medidas com bússola Clar. As medições foram inseridas no software OpenStereo ${ }^{\circledR}$ para cálculo do valor da média.
Princípios sobre o método de análise de elemento arquitetônico desenvolvido por Miall $(1985,1988,1996)$, para ambientes fluviais, foram aplicados como guia para analisar a relação entre as superfícies de descontinuidade, de modo que seu reconhecimento foi realizado a partir de um conjunto de hipóteses derivadas dos princípios da Superposição (Law of Superposition) e das Relações Transversais (Cross-Cutting Relations). Assim, para a atribuição de uma hierarquia às superfícies de descontinuidade, foram utilizadas as seguintes diretrizes: (1) as superfícies de maior continuidade lateral e que caracterizavam um 
único evento e/ou processo de deposição, foram tomadas como base e a elas foram atribuídas as maiores ordens do afloramento; (2) as demais superfícies foram classificadas de acordo com: (a) superfícies de menor ordem são delimitadas por superfícies de maior ordem; (b) superfícies que delimitam lâminas são consideradas de $1^{\text {a }}$ ordem; (c) caso sejam similares, um conjunto de superfícies pode ser considerado como de mesma ordem, mas o conjunto deve ser delimitado por uma superfície de ordem superior; (d) uma dada superfície pode truncar outra de igual ou menor ordem, mas nunca uma de ordem superior.

Para determinar a altitude das seções foi realizado nivelamento planialtimétrico sequencial com nível topográfico e mira, referenciado ao RN2049-L (IBGE). A paleoprofundidade de formação das fácies foi estimada conforme proposto por Souza et al. (2012), que consiste em considerar o contato entre as fácies que representam a base da face praial e o topo da face litorânea superior como correspondente ao nível médio de marébaixa à época de formação da barreira. Assim, para estimar o paleonível marinho durante a época de formação das fácies da barreira na área de estudo, foi considerada a altura do contato entre as fácies que representam a base da face praial e o topo da face litorânea superior, em relação ao nível médio do mar atual, que é de 1,5 $m$, acrescida da metade da amplitude média da maré atual, que é de $0,7 \mathrm{~m}$, o que resultou em um paleonível de + 2,2 m (Fig. 2)

A terminologia adotada para o perfil morfológico da praia foi baseada em Plint (2010), que delimita o perfil em três regiões: offshore, shoreface (face litorânea), a qual é subdividida em inferior, média e superior; foreshore (praia subaérea-intermaré).

A região offshore situa-se abaixo do nível base de ondas e tem como seu limite superior a lower shoreface (inferior); os processos de esbeltamento (shoaling) e quebra da onda (surf) ocorrem na região da middle e upper shoreface (média e superior); esta última é delimitada pelo foreshore, onde domina o processo de espraiamento (swash e backwash) após a quebra de ondas.

A terminologia adotada para a identificação das formas de fundo foi baseada em Walker (1992) e Dalrymple (2010), de forma que foram consideradas dunas $2 \mathrm{D}$ as de crista reta a linguóide e dunas 3D as de crista linguóide a sinuosa. Para o beach step (degrau da praia) foi adotada a definição segundo Hughes \& Turner (1999), que define essa forma de fundo como produto do limite entre os processos de surf e swash.

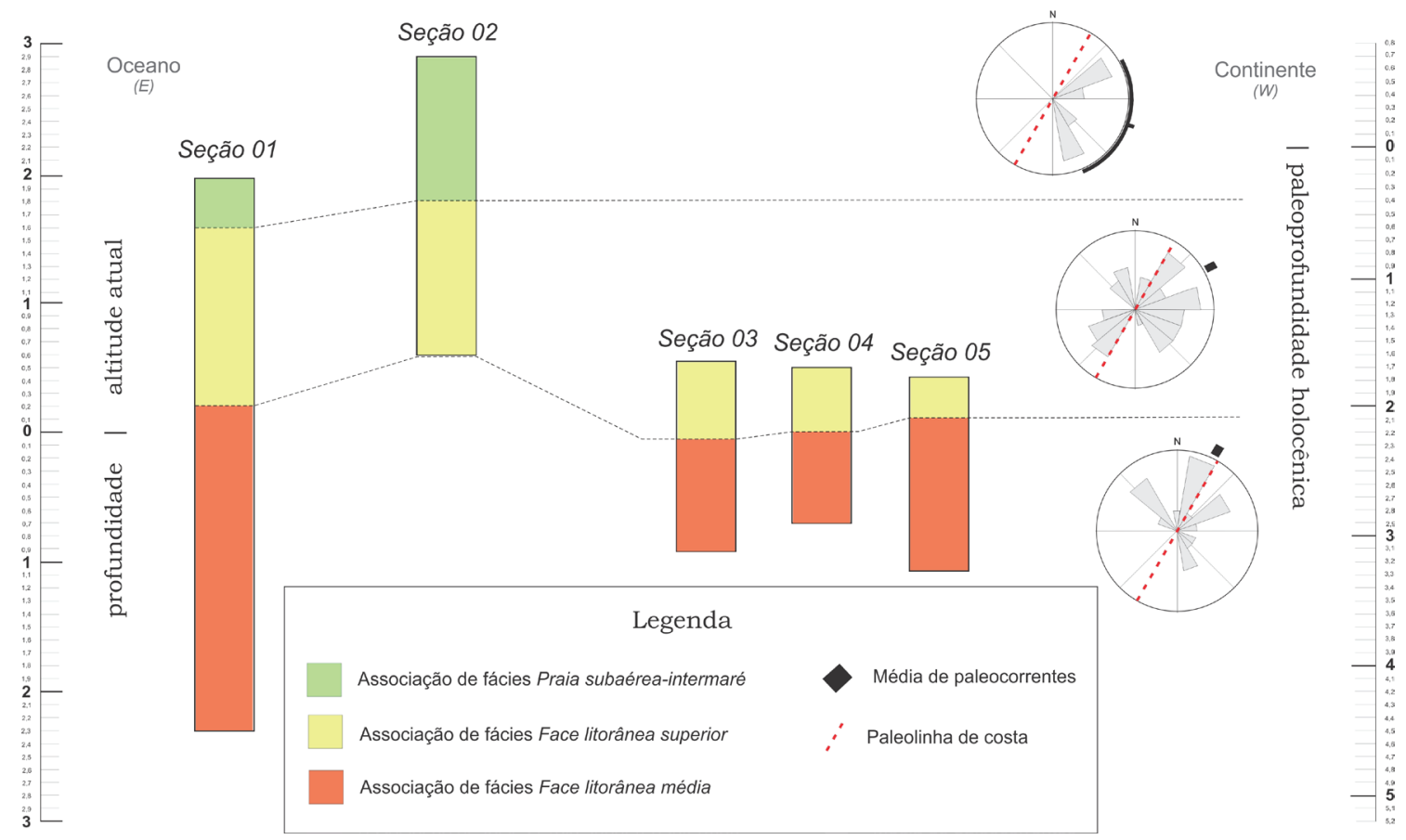

Figura 2. Desenho esquemático das seções descritas e das associações de fácies com suas respectivas profundidades. Figure 2. Schematic drawing of the sections described and the facies associations with their respective depths. 


\section{Resultados}

\section{1 Fácies}

Na área de estudo, a barreira é composta predominantemente por areia quartzosa muito fına a fina. Também ocorrem minerais pesados, matéria orgânica e fragmentos de troncos. Nas seções foram identificadas treze fácies: areia com estratificação cruzada plana (Sp), areia com estratificação cruzada acanalada (St), areia com estratificação cruzada de baixo ângulo (SI), areia com estratificação cruzada de baixo ângulo relacionada ao depósito de barras de arrebentação (SI(b)), areia com estratificação cruzada swaley (Ssc), areia com estratificação cruzada hummocky (Shc), areia com estratificação plano paralela (Sh), lama maciça (Fm), areia com estratificação cruzada sigmoide (Ss), areia com estratificação cruzada sigmoide do degrau da praia (Ss(b)), areia maciça $(\mathrm{Sm})$, areia maciça com bioturbação $(\mathrm{Sm}(\mathrm{b}))$ e areia com flaser (Sf).

A fácies Sp é formada por estratos com espessura de 3 a $40 \mathrm{~cm}$ em forma de cunha, contato inferior gradacional e granulação de areia muito fina a fina, muito bem a mal selecionada, pode ainda conter minerais pesados (Fig. 3). Podem ocorrer tubos Ophiomorpha sp. O rumo de mergulho predominante é para NE. Esta fácies foi interpretada como migração de dunas subaquosas 2D, com cristas retas a linguóides.

A fácies St é formada por estratos com espessura de 2 a $40 \mathrm{~cm}$ em forma de cunha, contato inferior erosivo e granulação de areia fina a grossa, bem a mal selecionada, com lâminas de minerais pesados (Fig. 4). Ocorrem tubos de Ophiomorpha sp. e lâminas deformadas por bioturbação. As direções de mergulho predominantes são para NW e NE. Esta fácies foi interpretada como correspondente à migração de dunas subaquosas 3D com cristas sinuosas e linguóides.

A fácies Sl é formada por estratos com espessura de 5 a $95 \mathrm{~cm}$ em forma tabular, contato inferior erosivo e granulação de areia muito fina a fina, muito bem a bem selecionada, podendo conter minerais pesados (Fig. 5A e 5B). Os rumos preferenciais são para E e SE. A interpretação dessa fácies é a de formação por fluxos na zona de espraiamento (face praial) em ambiente de pequena lâmina de água.

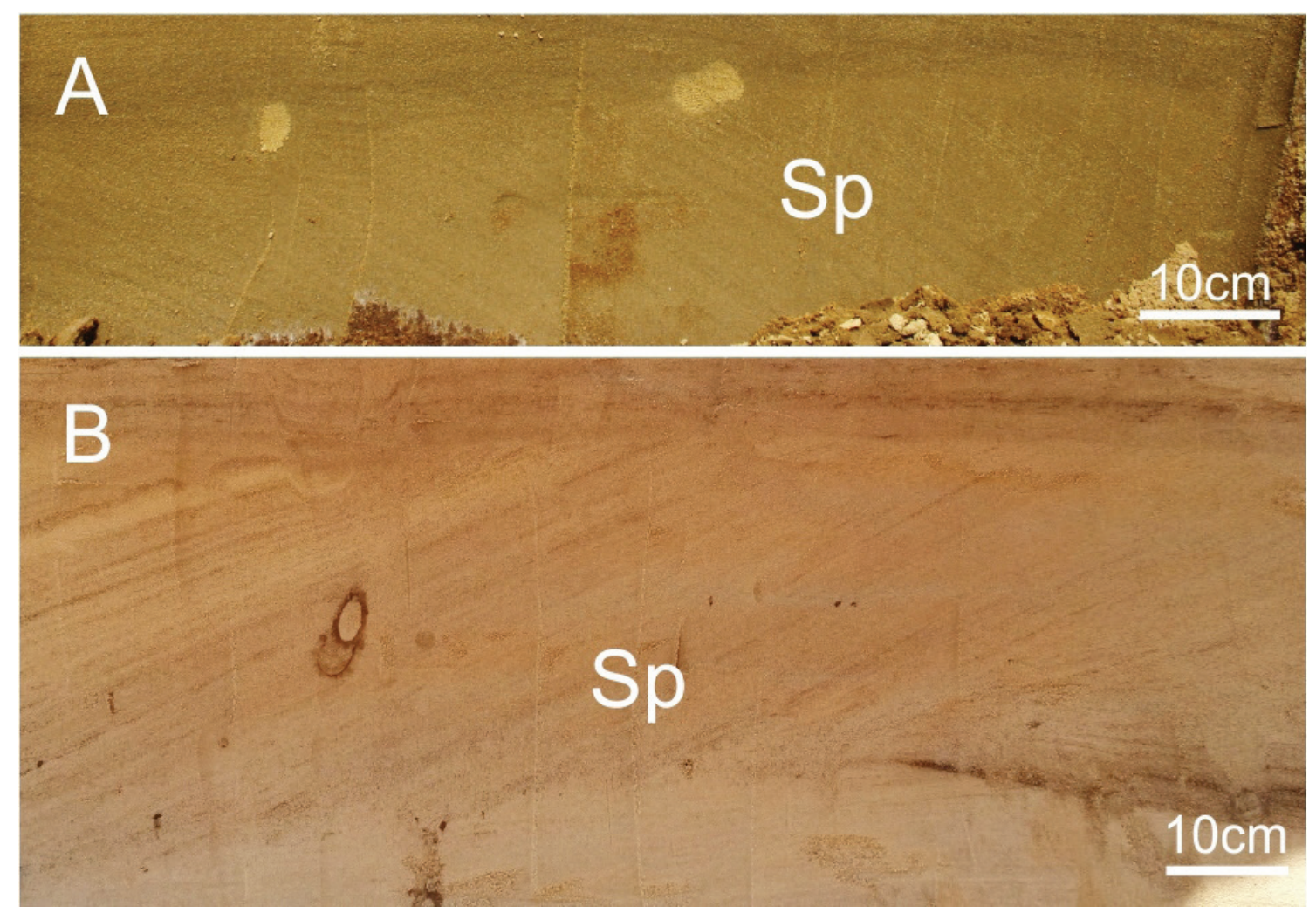

Figura 3. Areia com estratificação cruzada plana (Sp). A) Exemplo na Seção 1; B) Exemplo na Seção 4. Figure 3. Planar cross-stratified sand (Sp). A) Example in Section 1; B) Example in Section 4. 


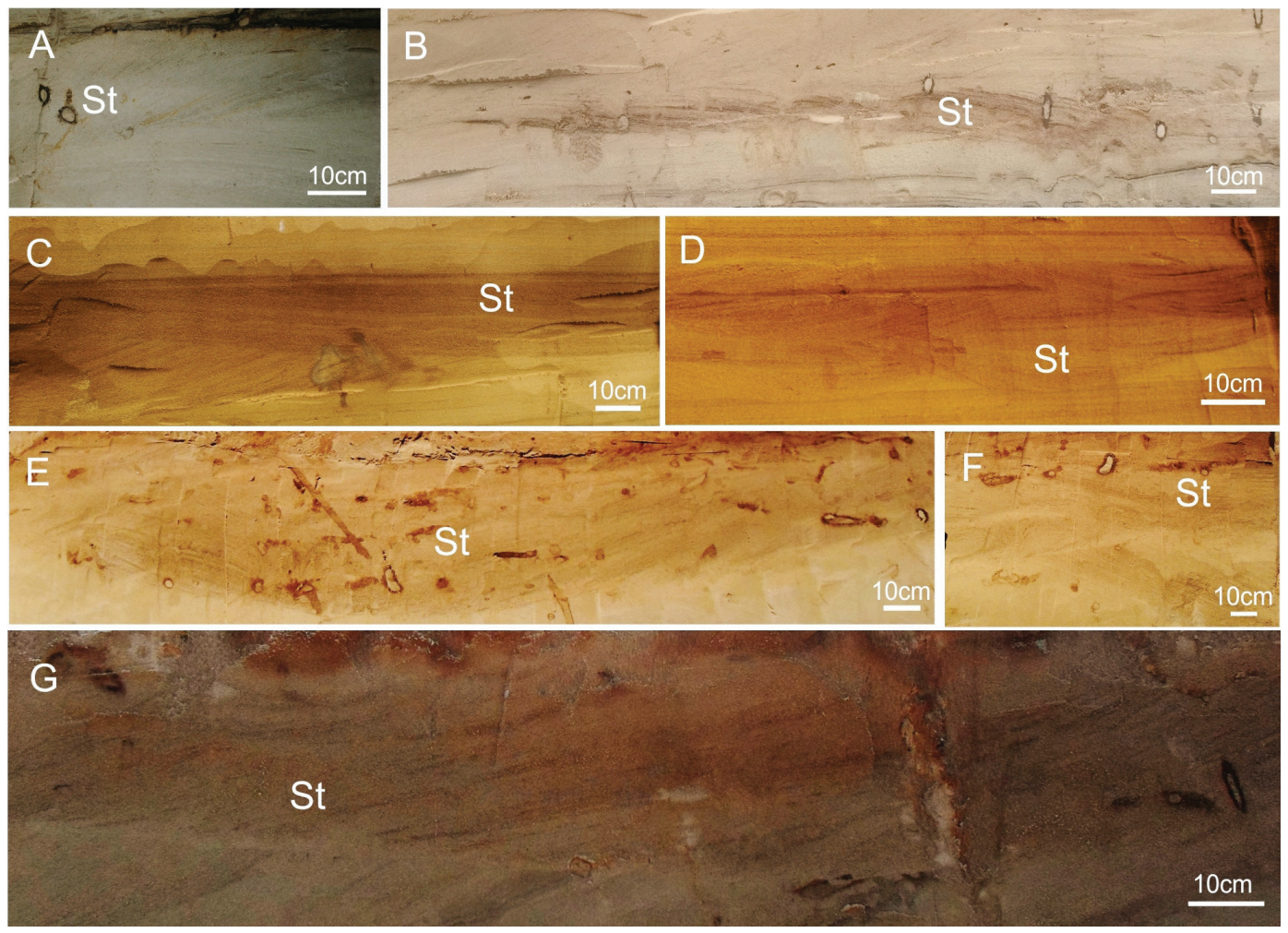

Figura 4. Areia com estratificação cruzada acanalada (St). A, D) Exemplos na Seção 1; B) exemplo na Seção 4; C) Exemplo na Seção 2; E, F) Exemplos na Seção 3; G) Exemplo na Seção 5.

Figure 4. Trough cross-stratified sand (St). A, D) Examples in Section 1; B) Example in Section 4; C) Example in Section 4; E, F) Examples in Section 3; (G) Example in Section 5.

A fácies SI(b) é formada por estratos com espessura de 10 a $20 \mathrm{~cm}$ em forma tabular, contato inferior erosivo e granulação de areia fina, bem selecionada, com abundância de minerais pesados (Fig. 5C). Presença de tubos de Ophiomorpha sp. e lâminas bastante deformadas por bioturbação. A interpretação dessa fácies é a de formação por fluxos trativos na região de arrebentação, relacionadas às feições de fundo de barras de arrebentação.

A fácies Ssc é formada por estratos lenticulares com espessura de 2 a $30 \mathrm{~cm}$, contato inferior erosivo, algumas vezes com estruturas wavy e granulação de areia muito fina a fina, muito bem a mal selecionada; contém lentes de minerais pesados intercalados com lentes de mica, detritos vegetais e fragmentos de troncos de até $15 \mathrm{~cm}$ (Fig. 6). Podem ocorrer lâminas deformadas por bioturbação. Os rumos preferenciais são para NE e NW. A interpretação dessa fácies é a de formação por fluxo oscilatório gerado por ondas, provavelmente de tempestade, e correntes.

A fácies Shc é formada por estrato com espessura de 1 a $15 \mathrm{~cm}$ e granulação de lentes de areia muito fina a fina, bem selecionada e com lâminas com concentração de minerais pesados intercaladas com lentes de matéria orgânica e mica (Fig. 7). Ocorrem tubos de Ophiomorpha sp. e lâminas deformadas por bioturbação. Esta fácies é formada por fluxo combinado, gerado correntes e ondas.

A fácies Sh é formada por estratos com espessura de 3 a $50 \mathrm{~cm}$ de areia muito fina a fina, muito bem selecionada, contém lâminas minerais pesados e pode conter lâminas de mica (Fig. 8). Ocorrem tubos de Ophiomorpha sp. e lâminas deformadas por bioturbação. A interpretação da fácies é a de formação em ambientes com correntes maior energia, as quais podem estar relacionadas, dentre outras causas, à passagem de tempestades.

A fácies $\mathrm{Fm}$ consiste de drapes com espessura de 1 a $3 \mathrm{~cm}$, possui contato inferior gradual e granulação de lama, podendo conter mica (Fig. 9). Ocorrem tubos Ophiomorpha sp. e lâminas deformadas devido à bioturbação. A interpretação dessa fácies é a de formação por decantação durante períodos hidrodinamicamente calmos. 


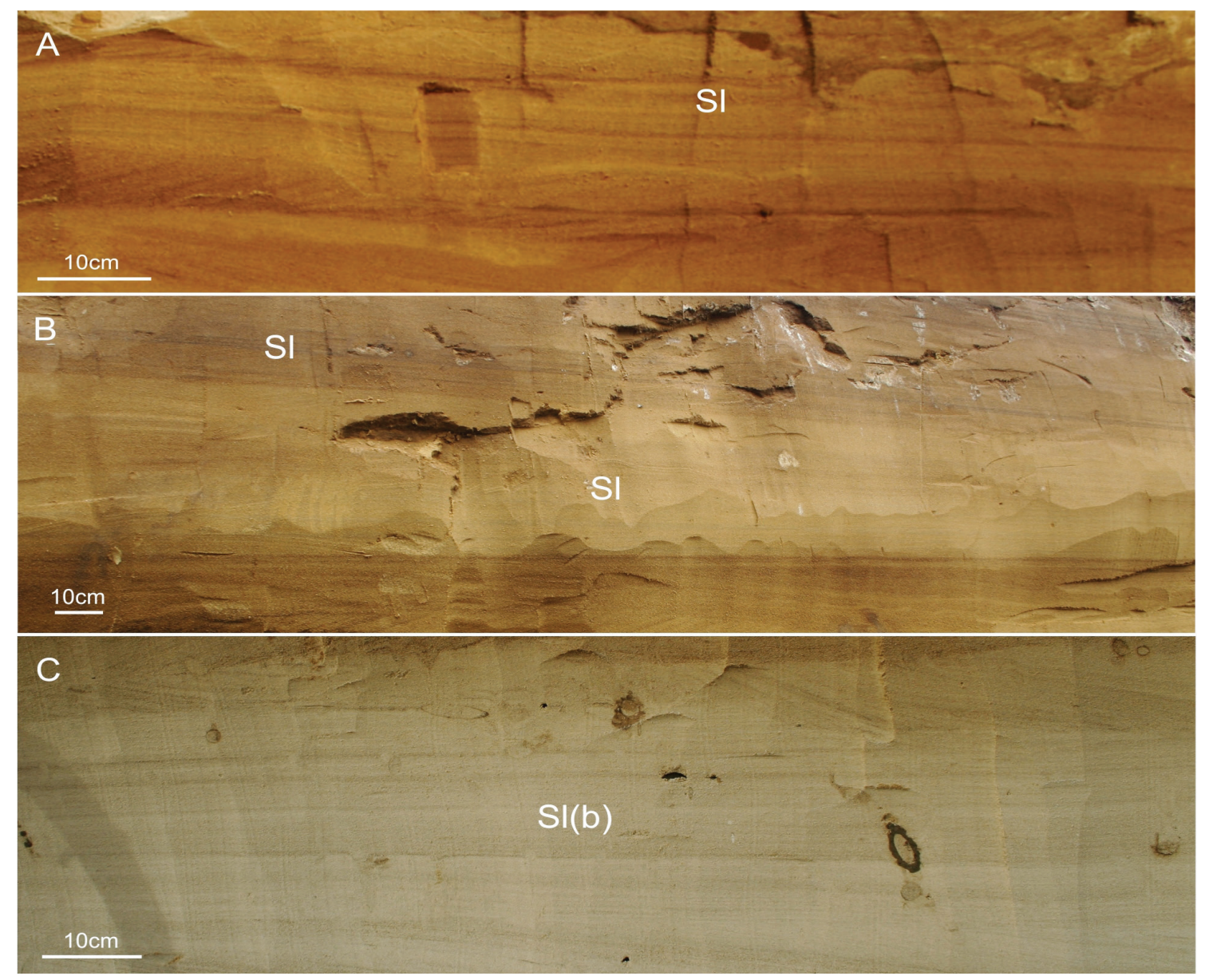

Figura 5: Areia com estratificação cruzada de baixo ângulo (SI). A) Exemplo na Seção 1; B) Exemplo na Seção 2 e Areia com estratificação cruzada de baixo ângulo relacionada ao depósito de barras de arrebentação. C) Exemplo na Seção 1. Figure 5: Low-angle cross-stratified sand (SI). A) Example in Section 1; B) Example in Section 2. Low-angle crossstratified sand related to submerse longshore bars. C) Example in Section 1.

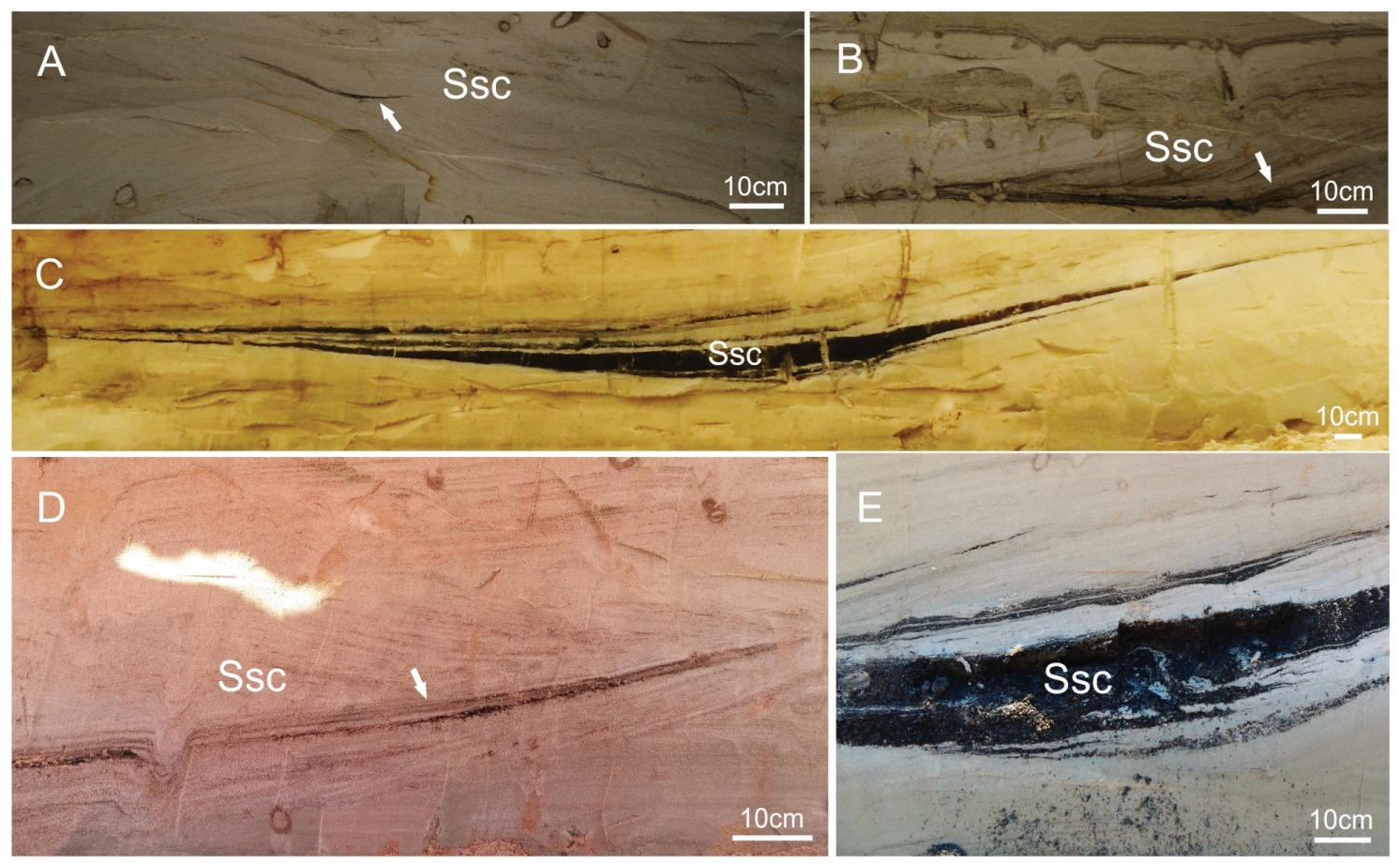

Figura 6. Areia com estratificação cruzada swaley (Ssc). A, B) Exemplo na Seção 1; C, D) Exemplo na Seção 4; E) Exemplo na Seção 5.

Figure 6. Swaley cross-stratified sand (Ssc). A, B) Examples in Section 1; C, D) Examples in Section 4; E) Example in Section 5. 


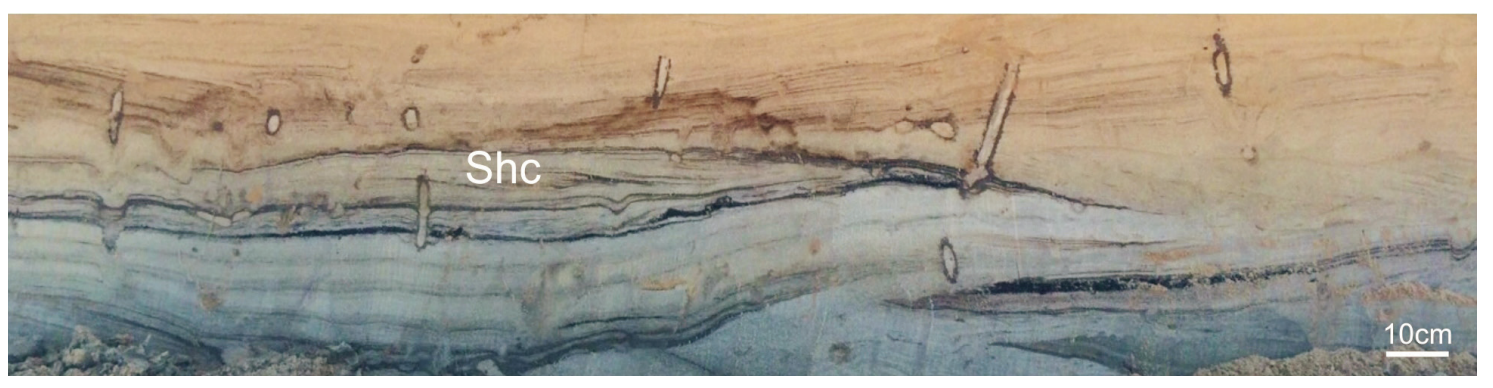

Figura 7. Areia com estratificação cruzada hummocky (Shc). Exemplo na Seção 4. Figure 7. Hummocky cross-stratified sand (Shc). Example in Section 4.

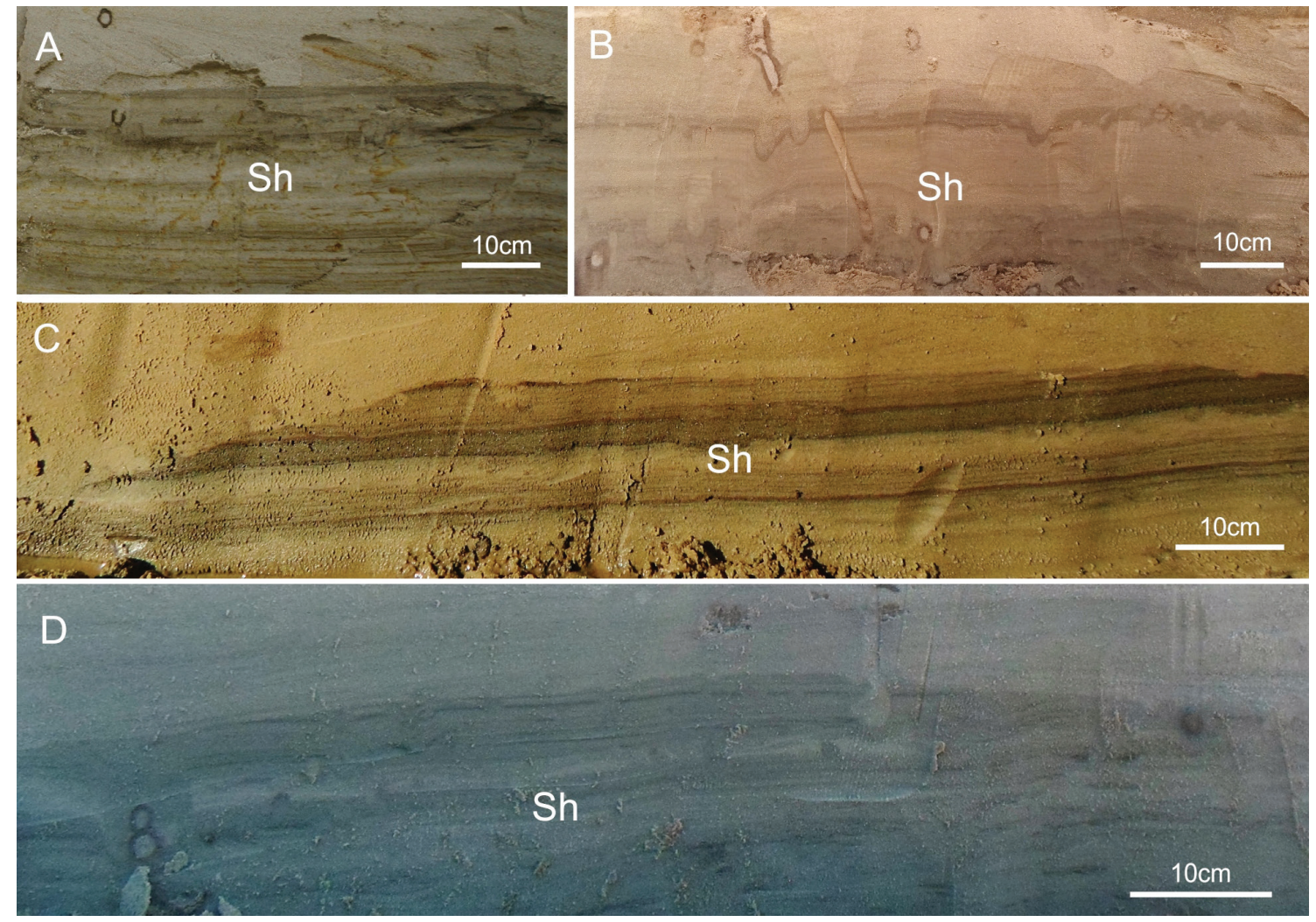

Figura 8. Areia com estratificação plano paralela (Sh). A) Exemplo na Seção 1; B) Exemplo na Seção 4; C) Exemplo na Seção 3; D) Exemplo na Seção 5.

Figure 8. Parallel laminated sand (Sh). A) Example in Section 1; B) Example in Section 4; C) Example in Section 3; D) Example in Section 5.

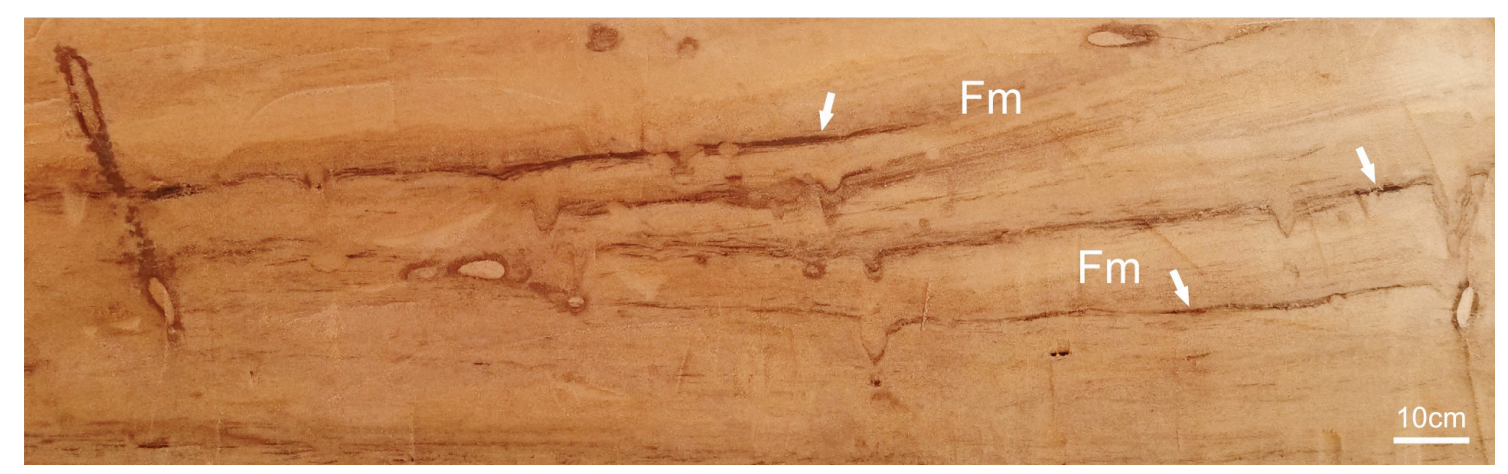

Figura 9. Lama maciça (Fm). Exemplo na Seção 4.

Figure 9. Massive mud (Fm). Example in Section 4. 
A fácies Ss é formada por estratos com espessura de 2 a $90 \mathrm{~cm}$ em forma de cunha e tabulares, contato inferior erosivo e granulação de areia muito fına a média, muito bem a mal selecionada, pode conter minerais pesados e drapes de lama e matéria orgânica associados às suas lâminas frontais (Fig. 10). Pode se apresentar como estratificação cruzada tangencial na base, devido à erosão da parte superior por superfícies de reativação. Ocorrem tubos de Ophiomorpha sp. e lâminas deformadas por bioturbação. As direções de mergulho são para NE e NW. Esta fácies foi interpretada como formada pela migração de dunas subaquosas 2D de crista reta, com alta carga de sedimento em suspensão.

A fácies Ss(b) é formada por estratos com espessura de 1 a $15 \mathrm{~cm}$ em forma de cunha e tabulares, contato inferior gradual e granulação de areia fina a grossa, moderadamente a mal selecionada (Fig. 11). Os rumos de mergulho são, preferencialmente, para NE e SE. A interpretação da fácies é a do degrau da praia, o qual tem sua formação no limite entre a zona de surf e espraiamento (swash).

A fácies $S m(b)$ é formada por estrato com espessura de 5 a $30 \mathrm{~cm}$, contato inferior gradual e granulação de areia muito fina a fina e muito bem selecionada (Fig. 12A). A ausência de estratificação aparente deve-se à presença abundante de bioturbação.

A fácies Sm é formada por estratos com espessura de 5 a $30 \mathrm{~cm}$ em cunha, contato inferior gradual e granulação de areia muito fina a fina, muito bem a bem selecionada; pode conter minerais pesados e matéria orgânica coloidal ou particulada (Fig. 12B e 12C). Há ausência de estratificação aparente e de bioturbação.
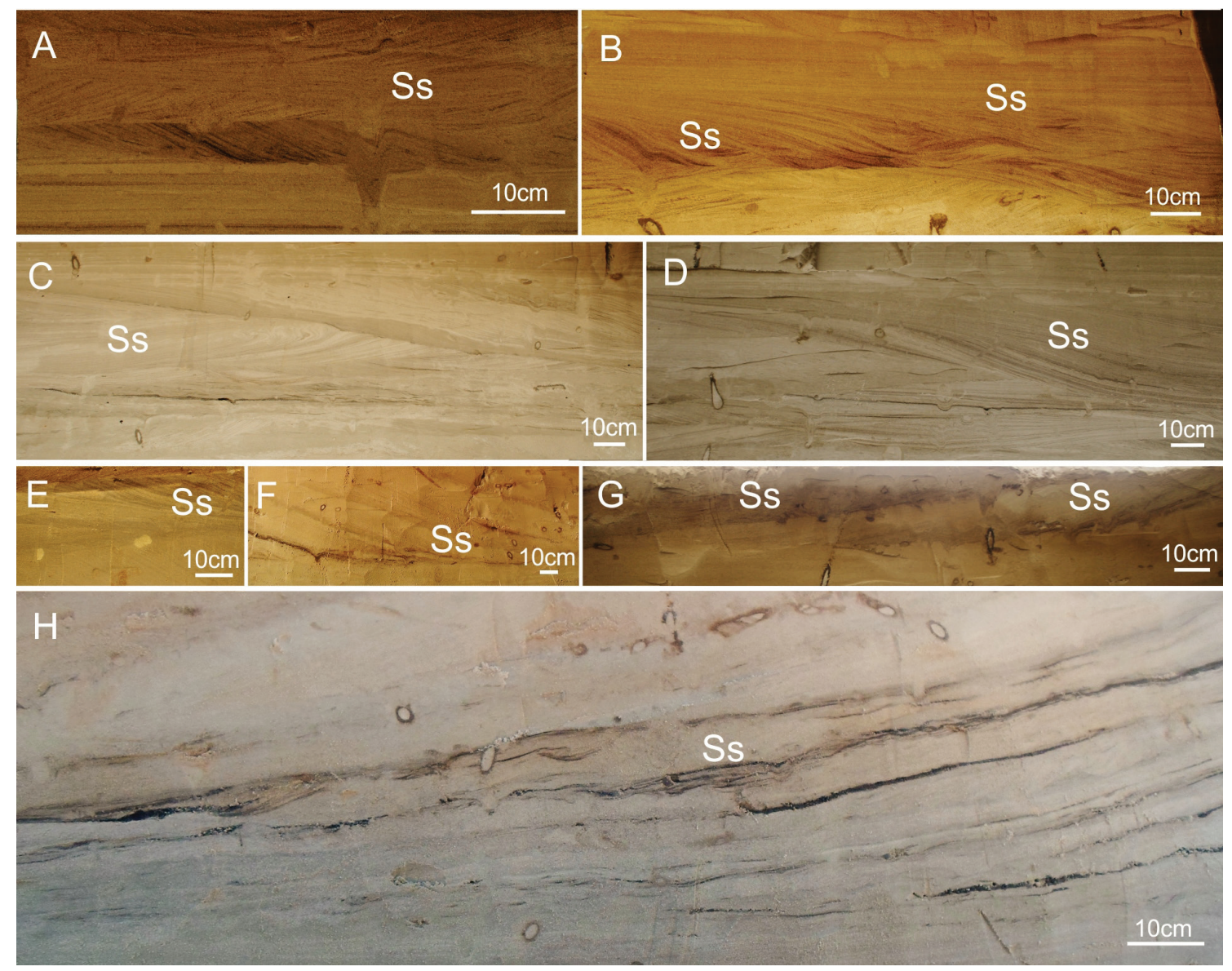

Figura 10. Areia com estratificação cruzada sigmoide (Ss). A, B, C, D) Exemplos na Seção 1; E) Exemplo na Seção 2; F) Exemplo na Seção 3; G, H) Exemplos na Seção 5.

Figure 10. Sigmoidal cross-stratified sand (Ss). A, B, C, D) Examples in Section 1; E) Example in Section 2; F) Example in Section 3; G, H) Examples in Section 5. 


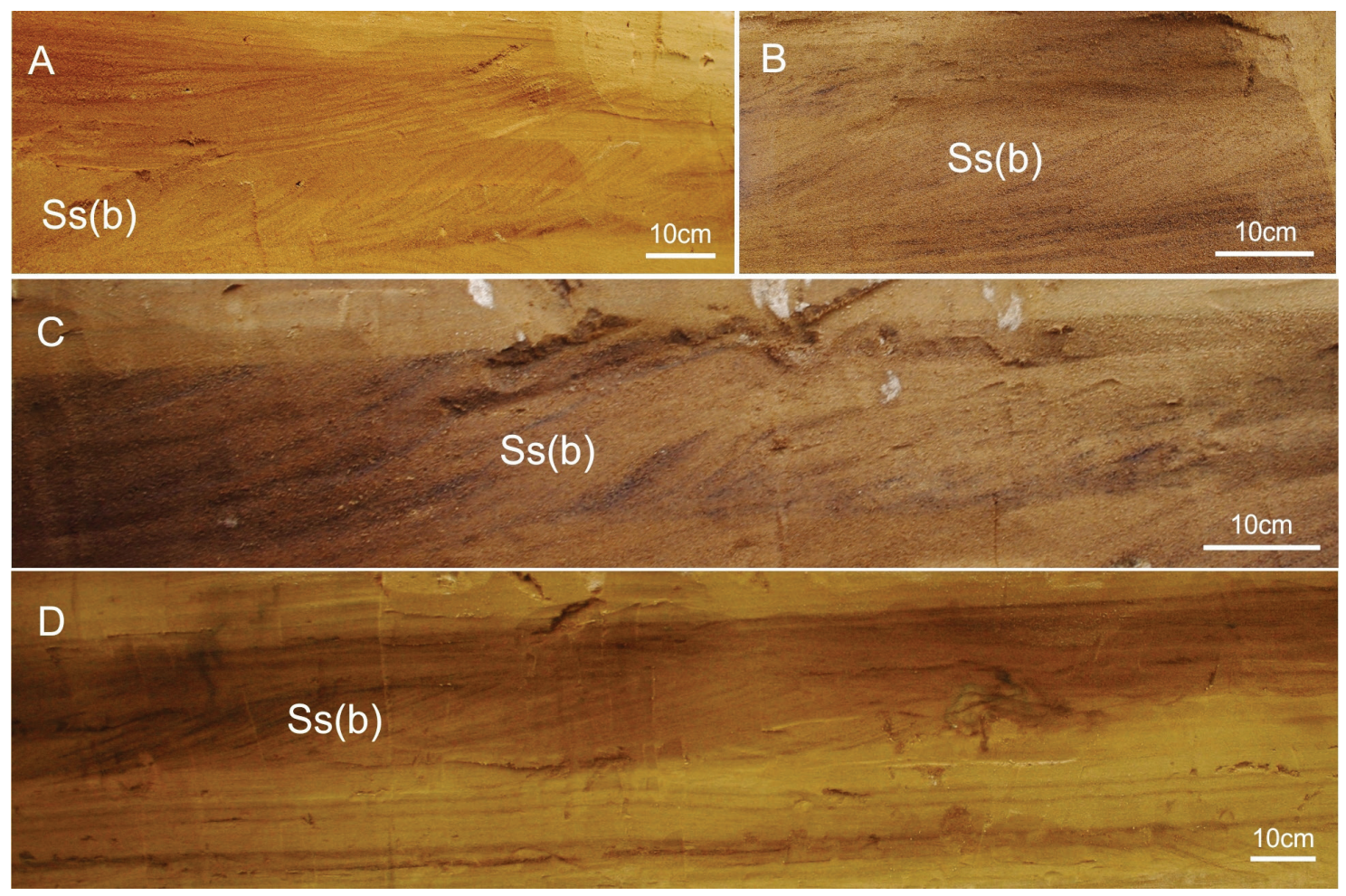

Figura 11. Areia com estratificação cruzada sigmoide do degrau da praia (Ss(b)). A) Exemplo na Seção 1; B, C, D) Exemplos na Seção 2.

Figure 11. Sigmoidal cross-stratified beach step sand (Ss(b)). A) Example in Section 1; B, C, D) Examples in Section 2.

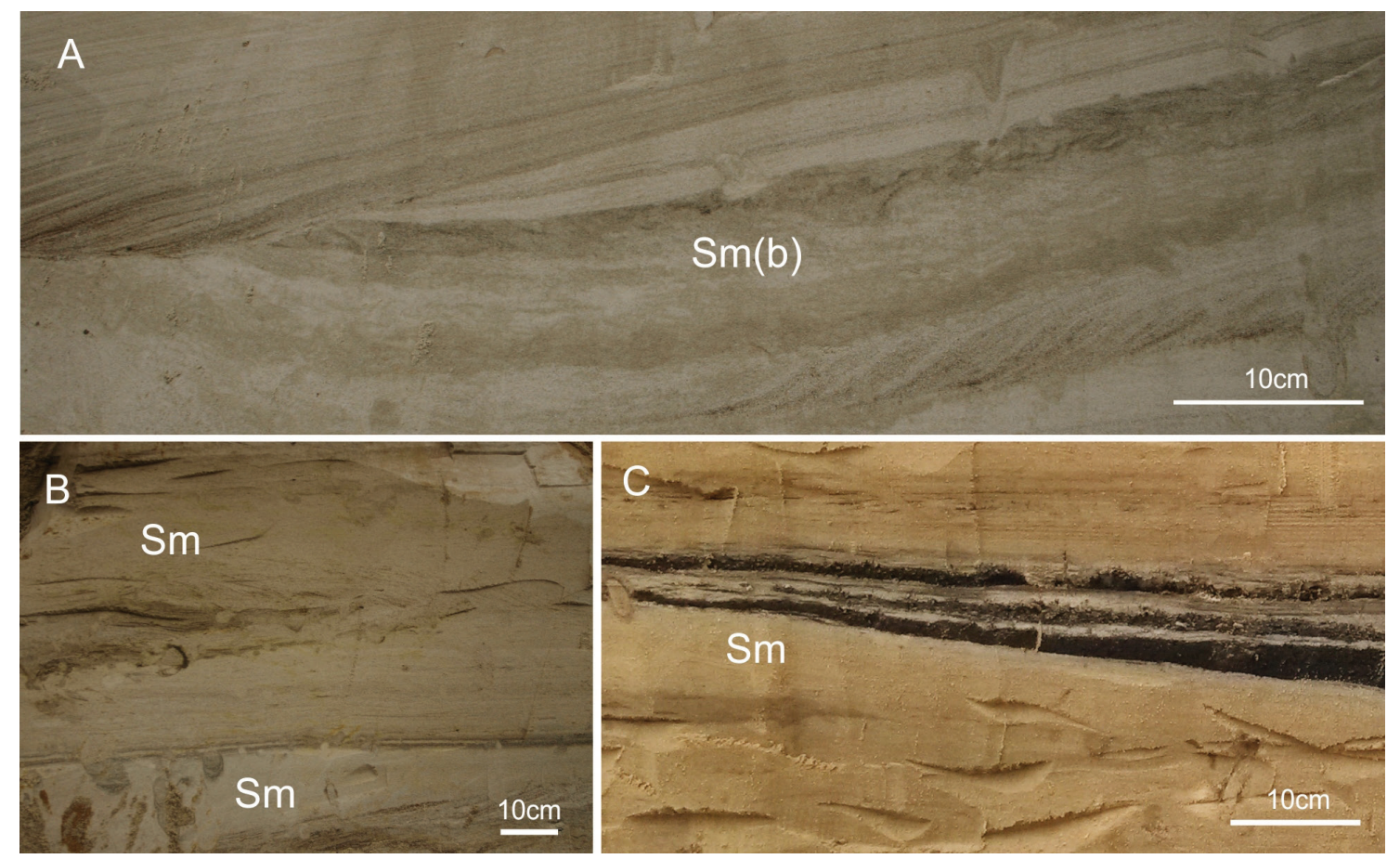

Figura 12. Areia maciça com bioturbação (Sm(b)). A) Exemplo na Seção 1. Areia maciça (Sm); B) Exemplo na Seção 1; C) Exemplo na Seção 4.

Figure 12. Massive sand with bioturbation (Sm(b)). A) Example in Section 1. Massive sand (Sm); B) Example in Section 1; C) Example in Section 4. 
A fácies Sf é formada por estratos com espessura de 10 a $40 \mathrm{~cm}$, contato inferior gradual e granulação de areia muito fına a fina, muito bem a mal selecionada com presença de minerais pesados; nas calhas, que variam de 0,5 a $7 \mathrm{~cm}$, observa-se matéria orgânica coloidal e mica, distribuídas de maneira não uniforme (Fig. 13). A Ocorrem tubos de Ophiomorpha sp. e lâminas deformadas por bioturbação. A interpretação dessa fácies é a de formação por fluxos gerados por ondas e correntes, seguidos por deposição de lama e detritos vegetais durante períodos hidrodinamicamente mais calmos.

\subsection{Superfícies de descontinuidade}

Nas seções foram reconhecidas superfícies de descontinuidade de $1^{a}, 2^{a}$ e $3^{a}$ ordem. As superfícies de $1^{\text {a }}$ ordem limitam estratos cruzados individuais do mesmo tipo, com pouca ou nenhuma erosão interna associada. Essas superfícies separam sequências rítmicas de pequena escala, mostrando continuidade na sedimentação (Fig. 14A, 15A, 16A, 17A e 18A).

As superfícies de $2^{a}$ ordem limitam as de $1^{\text {a }}$ ordem. Aquelas truncam distintas estruturas deposicionais, as quais podem, ou não, estarem associadas ao mesmo processo de deposição e direção do fluxo. Representam variações na direção ou característica do fluxo (Fig. 14B, 15B, 16B, 17B e 18B) e apresentam geometria externa tabular, lenticular e em cunha.

As superfícies de $3^{a}$ ordem limitam as superfícies de $2^{a}$ ordem. Aquelas estendemse por toda a seção e delimitam depósitos oriundos de eventos de maior energia ou de distintos processos de deposição. Representam mudanças nas formas de fundo provocadas por eventos sazonais de alta energia (associados à passagem de frentes) ou devido às mudanças hidrodinâmicas do fluxo dentro do sistema praial (Fig. 14C, 15C, 16C, 17C e 18C) e apresentam geometria externa tabular ou lenticular.

\subsection{Associações de fácies}

Foram reconhecidas três associações de fácies, interpretadas como correspondentes à face litorânea média (middle shoreface), face litorânea superior (upper shoreface) e praia subaérea-intermaré (foreshore).

A associação Face Litorânea Média (FLM) é caracterizada pelas fácies Ssc, Sh, Fm, Sf, Sm, Ss e Shc. Possui alto grau de bioturbação. É definida, principalmente, pela fácies Ssc, a qual
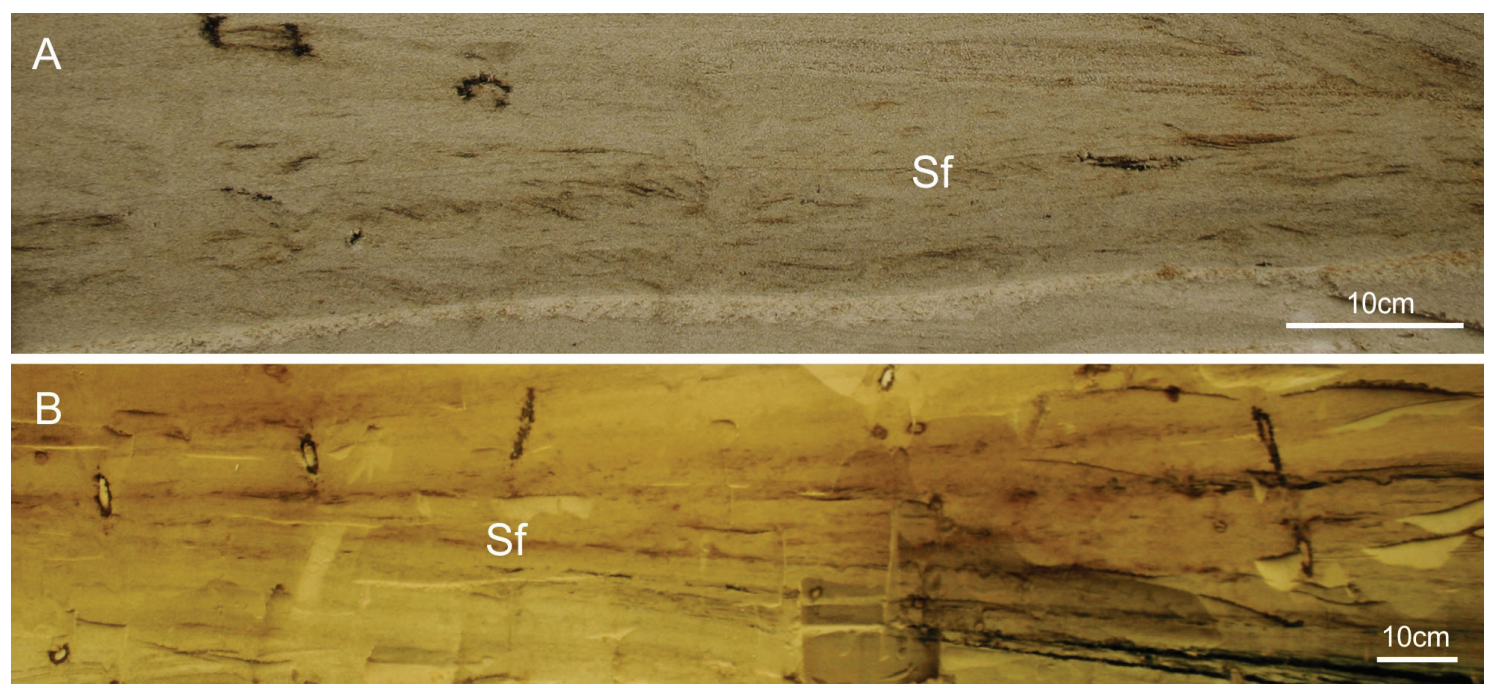

Figura 13.: Areia com flaser (Sf). A) Exemplo na Seção 1; B) Exemplo na Seção 4. Figure 13.: Flaser sand (Sf). A) Example in Section 1; B) Example in Section 4. 



Figura 14. Superfícies identificadas na Seção 1: A) Superfície de $1^{\text {a }}$ ordem; B) Superfície de $2^{\text {a }}$ ordem; C) Superfície de $3^{\text {a }}$ ordem; D) Parte superior na Seção 1; E) Parte inferior na Seção 1. Topo de seção 2,0 m acima do nível médio do mar atual e base da seção $2,5 \mathrm{~m}$ abaixo do nível médio do mar atual.

Figure 14. Surfaces identified in Section 1. A) 1st order surface; B) 2nd order surface; C) 3rd order surface; D) upper part of Section 1; E) bottom part of the Section 1. Top of Section $2.0 \mathrm{~m}$ above of current mean sea level e bottom of Section $2.5 \mathrm{~m}$ below the current mean sea level.

possui rumo de mergulho para a costa (onshore) e é composta de areia muito fina a fina, com presença de matéria orgânica particulada e fragmentos de madeira. Corresponde à deposição de sedimento, principalmente, por correntes provenientes de fluxos oscilatórios, mas também por fluxos trativos e decantação, que ocorrem na zona de esbeltamento (shoalling zone), próximo à zona de quebra de onda. Esta associação ocorre entre 2,2 m e 4,5 m de paleoprofundidade e foi identificada na Seção 1, Seção 3, Seção 4 e Seção 5 (Fig. 19B, 21B, 22B e 23B).
A associação Face Litorânea Superior (FLS) é caracterizada, na sua parte inferior, pelas fácies St, Sp e Ss, e pelas fácies St, Ss(b), Sp e Ss em sua parte superior. Observa-se a mudança lateral da fácies Ss(b) para SI. A ciclicidade em sua granulação, alternância entre areia e matéria orgânica coloidal, observada nas lâminas frontais da fácies Ss é atribuída à variação da velocidade das correntes de deriva devido a variação do nível do mar durante o ciclo das marés. As lâminas deformadas indicam processos de fluidificação e intensa bioturbação. As fácies foram formadas 
NE

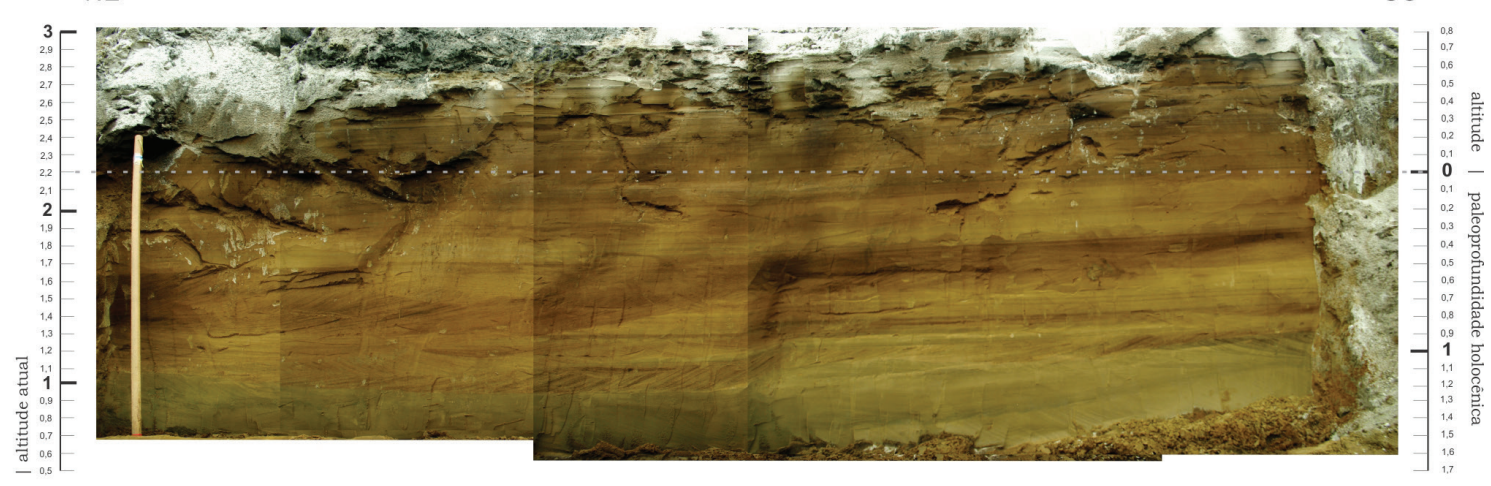

NE

so
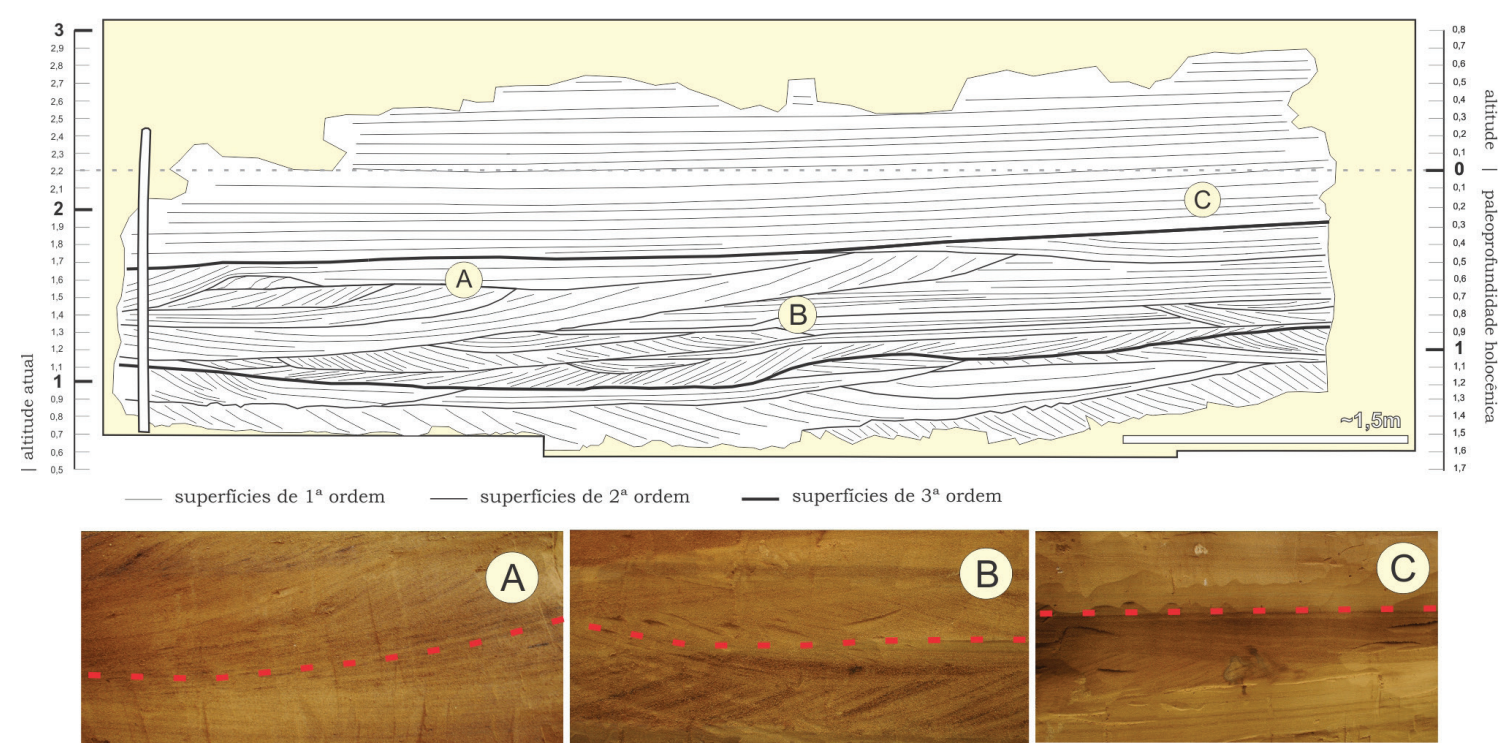

Figura 15. Superfícies identificadas na Seção 2. A) Superfície de $1^{\text {a }}$ ordem; B) Superfície de $2^{a}$ ordem; C) Superfície de $3^{\text {a }}$ ordem. Topo da seção 2,8 m acima do nível médio do mar atual e base da seção 0,6m abaixo do nível médio do mar atual. Figure 15. Surfaces identified in Section 2. A) 1st order surface; B) 2nd order surface; C) 3rd order surface. Top of Section $2.8 \mathrm{~m}$ above of current mean sea level e bottom of Section $0.6 \mathrm{~m}$ below the current mean sea level.

por fluxos trativos de regime inferior, gerados por ondas na zona de quebra e de surfe em uma face litorânea com barras e canais. Esta associação ocorre entre 0,6 e 2,2 m de paleoprofundidade e foi identificada na Seção 1, Seção 2, Seção 3, Seção 4 e Seção 5 (Fig. 19A, 20B, 21B, 22B e 23B).

A associação Praia Subaérea-intermaré (PSI) é caracterizada pelas fácies SI, Ss(b), Sp e St. Observa-se a fácies SI truncada por Ss(b) e St e algumas Sp, as quais são oriundas de pequenos canais. Possui pouca bioturbação. Corresponde à deposição de sedimento por provável regime de fluxo de transição a superior na zona de espraiamento (face praial), além de sedimento depositado no pós-praia. Esta associação ocorre entre 0,6 $\mathrm{m}$ de paleoprofundidade e 0,8 $\mathrm{m}$ de paleoaltitude e foi identificada no topo da Seção 1 e Seção 2 (Fig. 19A e 20B).

\section{Discussão}

\subsection{Associações de fácies e superfícies de des- continuidade}

Nas associações de fácies PSI e FLS, as superfícies de maior continuidade lateral $\left(^{a}\right.$ ordem) estão relacionadas aos depósitos da face praial (SI) (Fig. 14D), à migração de barras de arrebentação (SI(b)) (Fig. 19A) e à migração de dunas subaquosas com cristas retas (Ss) (Fig. 20B).

Na associação de fácies FLM, as superfícies de $3^{a}$ ordem estão relacionadas à ação de fluxos oscilatórios e/ou combinados (Ssc e Sf). Estas superfícies juntamente a seus depósitos (Fig. 22A e 23A) sugerem eventos de alta energia, os quais estão associados à formação de grandes 
SE

NO

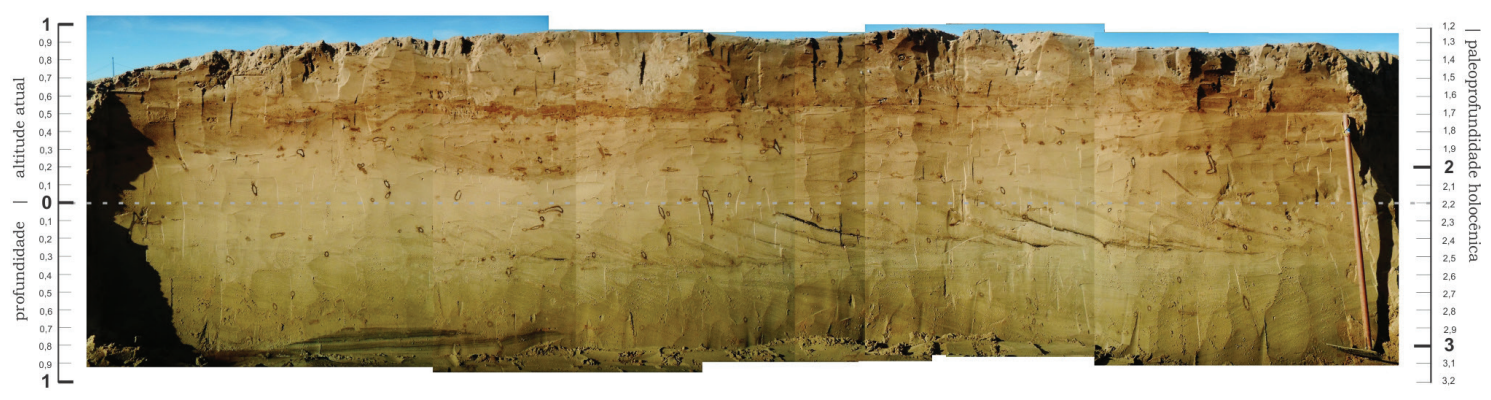

SE

NO
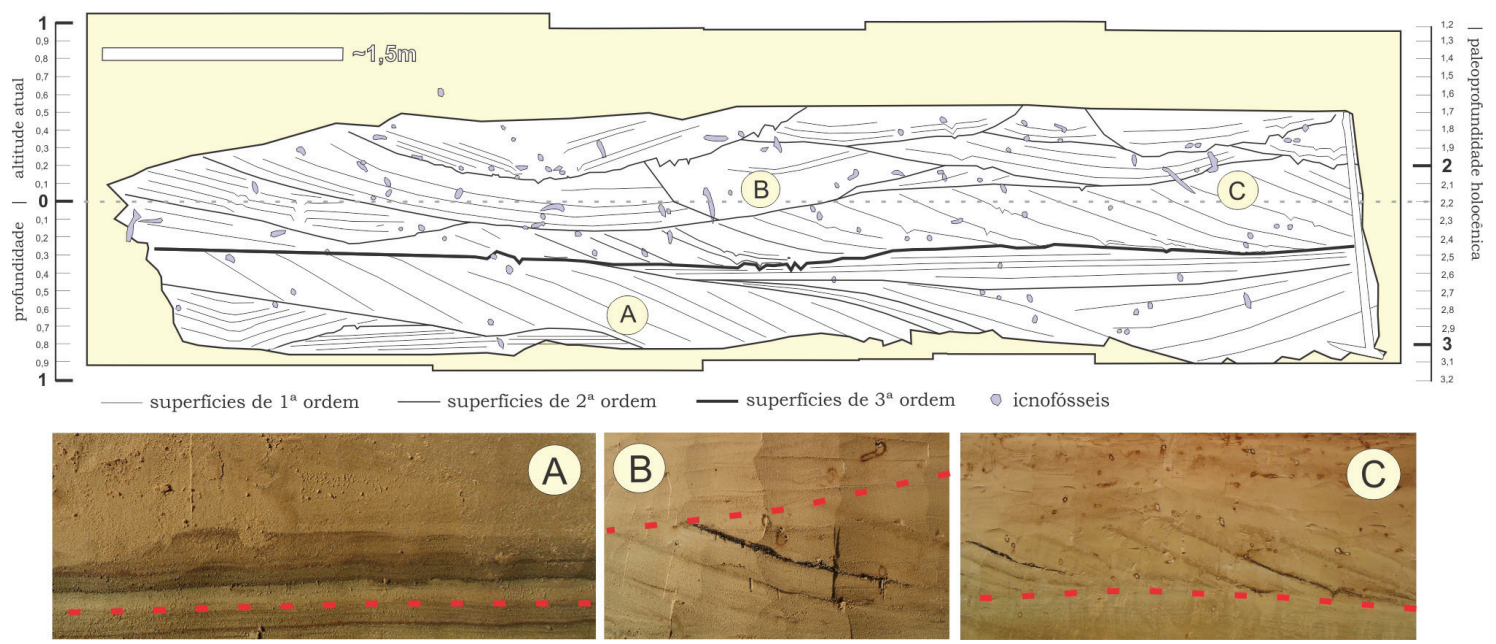

Figura 16. Superfícies identificadas na Seção 3. A) Superfície de $1^{\text {a }}$ ordem; B) Superfície de $2^{\mathrm{a}}$ ordem; C) Superfície de $3^{\mathrm{a}}$ ordem. Topo da seção 0,5 m acima do nível médio do mar atual e base da seção 0,9m abaixo do nível médio do mar atual. Figure 16. Surfaces identified in Section 3. A) 1st order surface; B) 2nd order surface; C) 3rd order surface. Top of Section $0.5 \mathrm{~m}$ above of current mean sea level e bottom of Section $0.9 \mathrm{~m}$ below the current mean sea level.

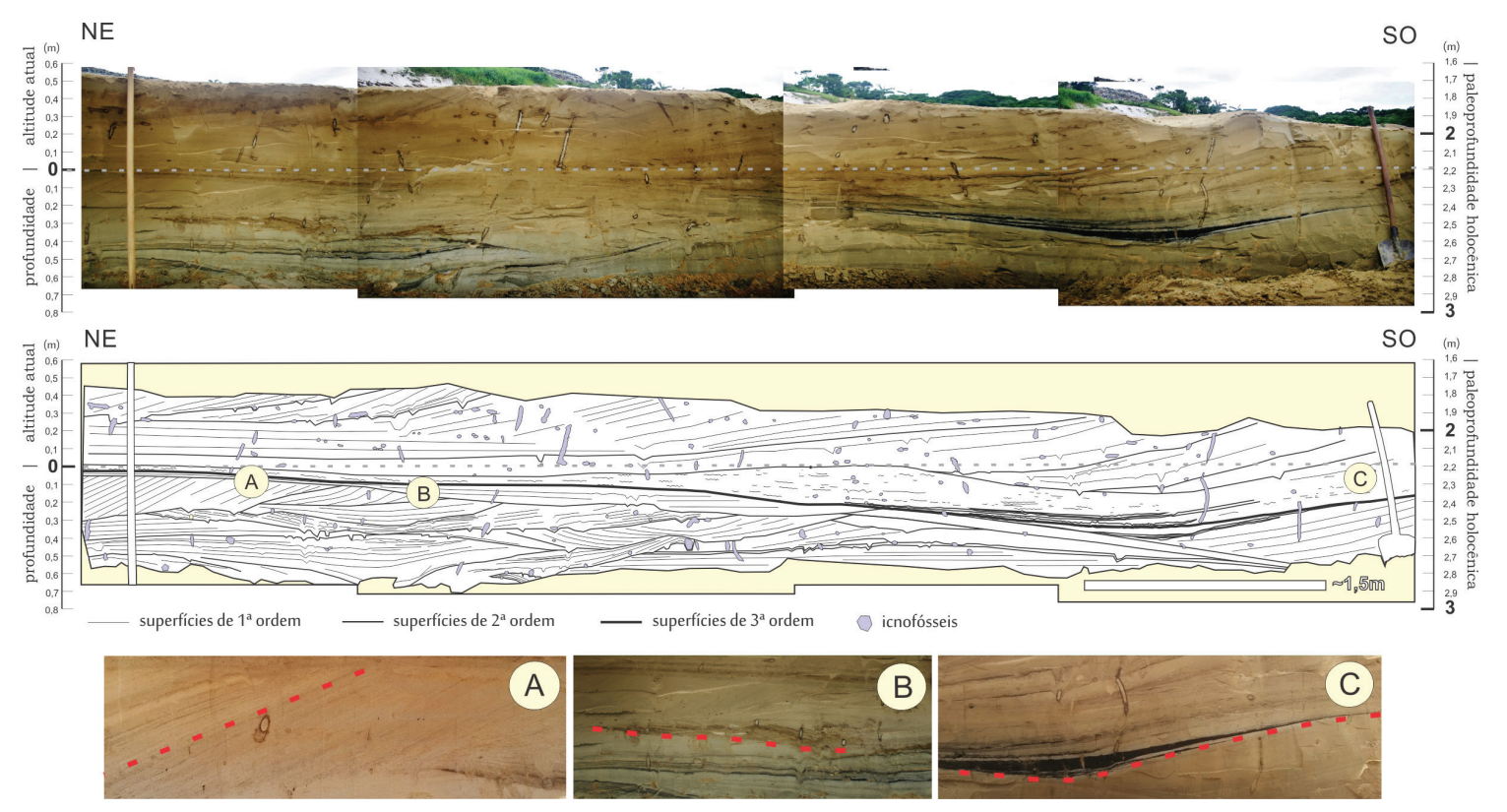

Figura 17. Superfícies identificadas na Seção 4. A) Superfície de $1^{\text {a }}$ ordem; B) Superfície de $2^{a}$ ordem; C) Superfície de $3^{\text {a }}$ ordem. Topo da seção 0,5 m acima do nível médio do mar atual e base da seção 0,7 $\mathrm{m}$ abaixo do nível médio do mar atual. Figure 17. Surfaces identified in Section 4. A) 1st order surface; B) 2nd order surface; C) 3rd order surface. Top of Section $0.5 \mathrm{~m}$ above of current mean sea level e bottom of Section $0.7 \mathrm{~m}$ below the current mean sea level. 

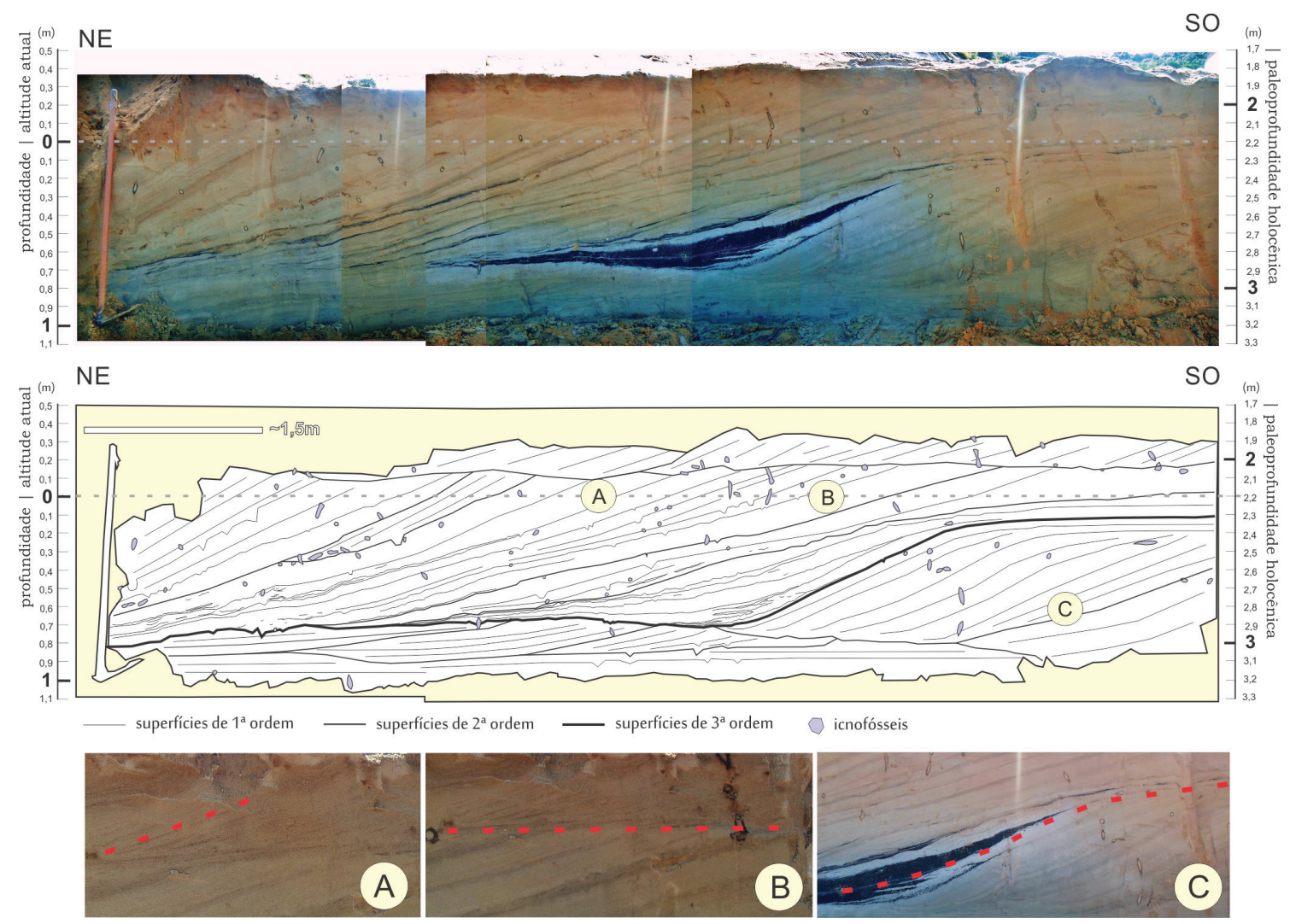

Figura 18. Superfícies identificadas na Seção 5. A) Superfície de $1^{\mathrm{a}}$ ordem; B) Superfície de $2^{\mathrm{a}}$ ordem; C) Superfície de $3^{\mathrm{a}}$ ordem. Topo da seção 0,3m acima do nível médio do mar atual e base da seção 1,0 $\mathrm{m}$ abaixo do nível médio do mar atual. Figure 18. Surfaces identified in Section 5. A) 1st order surface; B) 2nd order surface; C) 3rd order surface. Top of Section $0.3 \mathrm{~m}$ above of current mean sea level e bottom of Section $1.0 \mathrm{~m}$ below the current mean sea level.

estruturas tipo swaley, geradas por tração e decantação, que podem ter sido preservadas em ambientes mais rasos, entre 2,3 e 4,0 $\mathrm{m} \pm$ $0,7 \mathrm{~m}$ de paleoprofundidade, quando comparado ao trabalho de Souza et al. (2012) devido à uma possível influência de um delta de maré vazante (ebb-tidal delta); que funcionaria como uma proteção contra a ação de ondas severas após a tempestade que construiu o depósito. Isto explicaria a decorrência de drapes de lapa, matéria orgânica particulada e detritos vegetais de forma rítmica no depósito; além da influência direta das correntes de maré, as quais também poderiam ter contribuído (componente unidirecional) para o padrão assimétrico observado na fácies Ssc da Seção 5 (Fig. 23A). Segundo Angulo (1999, 2004), no litoral paranaense os deltas de maré vazante são mais desenvolvidos que os de enchente.

Ainda na associação FLM, também quando comparado à paleoprofundidade das fácies encontradas por Souza et al. (2012), as fácies Fm e Shc foram encontradas na Seção 4 em paleoprofundidades mais rasas, entre 2,1 e 2,9 m $\pm 0,7 \mathrm{~m}$. Estas estruturas, geradas sob influência de fluxos oscilatórios de alta energia, também poderiam ter sido preservadas devido à influência do possível delta de maré vazante. Angulo (2004) apresenta um modelo de delta de maré vazante para a Bahia de Guaratuba, no qual contém: barras de espraiamento e barras submersas; barra de margem de canal; lobo terminal; canal principal de vazante; direção inferida da deriva litorânea predominante e outras unidades.

A complexidade e dinâmica do ambiente é justificada pela interação de correntes de maré, correntes de deriva litorânea e ondas. Estudos hidrodinâmicos quantitativos e modelagens numéricas, em ambientes análogos, demonstram amplas variações nas velocidades e direções dos fluxos associados (e.g. Hansen et al., 2013; Jia et al., 2015; Spydell et al., 2015; Harrison et al., 2017). A evolução desses ambientes, devido às alterações da hidrodinâmica local em maior escala temporal, resulta na migração dos 

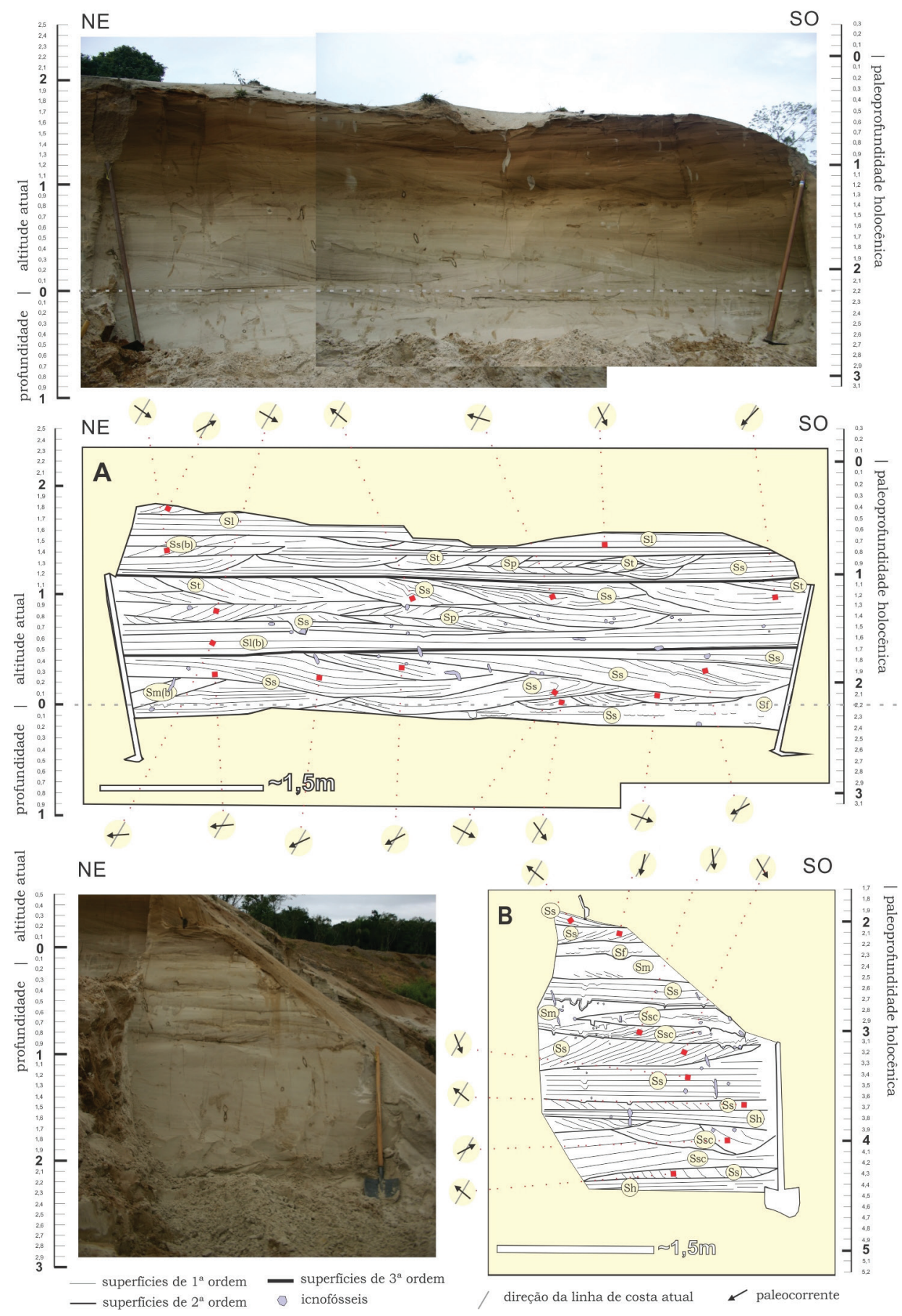

Figura 19. Seção 1 e seu fotomosaico com descrição. A) Parte superior da Seção 1; B) Parte inferior da Seção 1 . Areia com estratificação cruzada plana (Sp); Areia com estratificação cruzada acanalada (St); Areia com estratificação cruzada plana de baixo ângulo relacionada ao deposito de barras de arrebentação (SI(b)); Areia maciça (Sm); Areia com estratificação cruzada de baixo ângulo (SI); Areia com estratificação cruzada sigmoide (Ss); Areia com estratificação cruzada sigmoide do "pé da praia" (Ss(b)); Areia com estratificação cruzada swaley (Ssc); Areia com flaser (Sf); Areia com estratificação plano paralela (Sh).

Figure 19. Section 1 and its photomontage with description. A) Upper part of Section 1; B) Bottom part of the Section 1. Planar cross-stratified sand (Sp); Trough cross-stratified sand (St); Low-angle cross-stratified sand related to submerse bars (SI(b)); Massive sand (Sm); Low-angle cross-stratified sand (SI); Sigmoidal cross-stratified sand (Ss); Sigmoidal cross-stratified beach step sand (Ss(b)); Swaley cross-stratified sand (Ssc); Flaser sand (Sf); Parallel laminated sand (Sh). 
NE
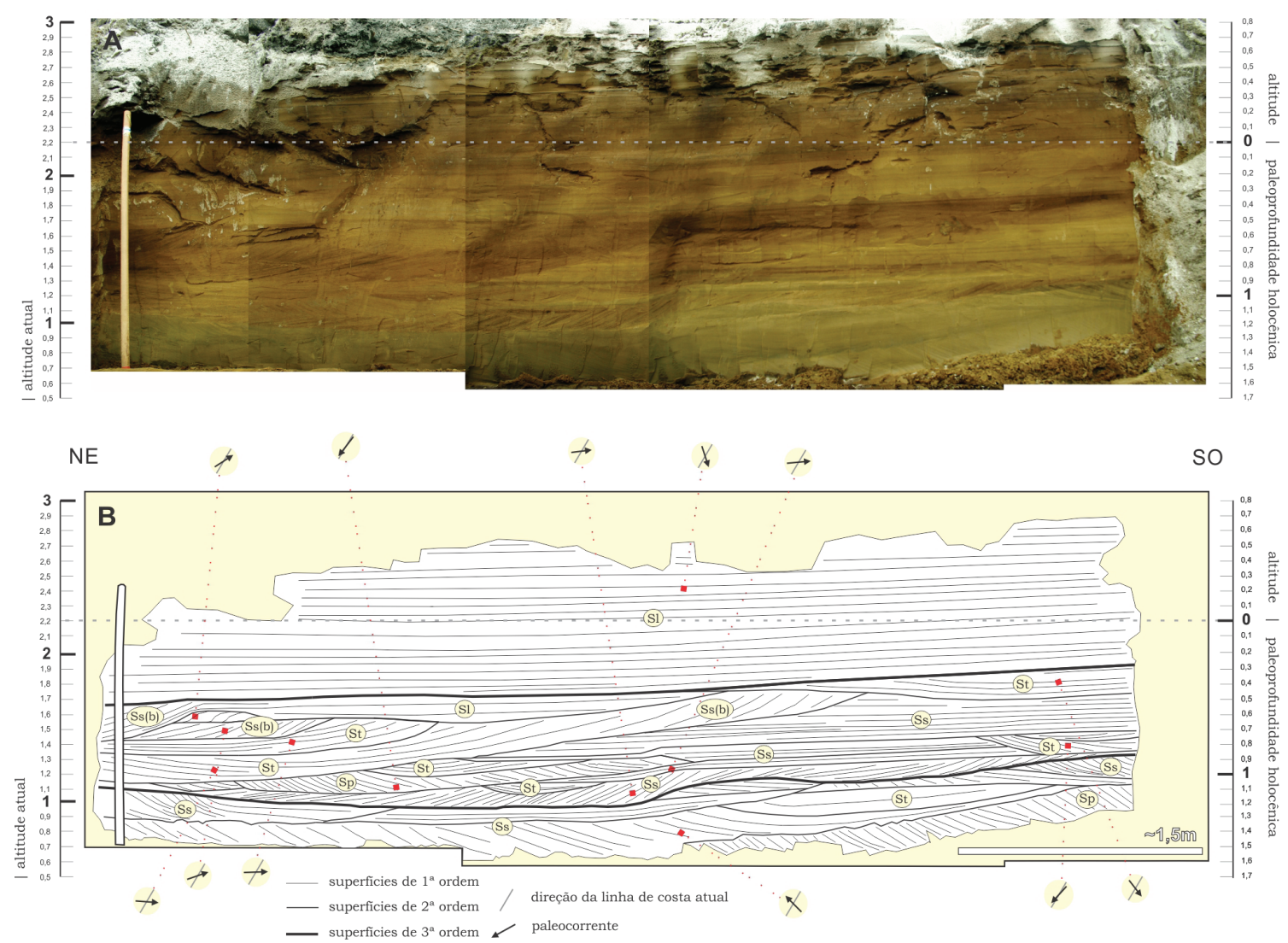

Figura 20. Seção 2 (A) e seu fotomosaico com descrição (B). Areia com estratificação cruzada plana (Sp); Areia com estratificação cruzada acanalada (St); Areia com estratificação cruzada de baixo ângulo (SI); Areia com estratificação cruzada sigmoide (Ss); Areia com estratificação cruzada sigmoide do "pé da praia" (Ss(b)).

Figure 20. Section 1 (A) and its photomontage with description (B). Planar cross-stratified sand (Sp); Trough crossstratified sand (St); Low-angle cross-stratified sand (SI); Sigmoidal cross-stratified sand (Ss); Sigmoidal cross-stratified beach step sand (Ss(b)).

SE
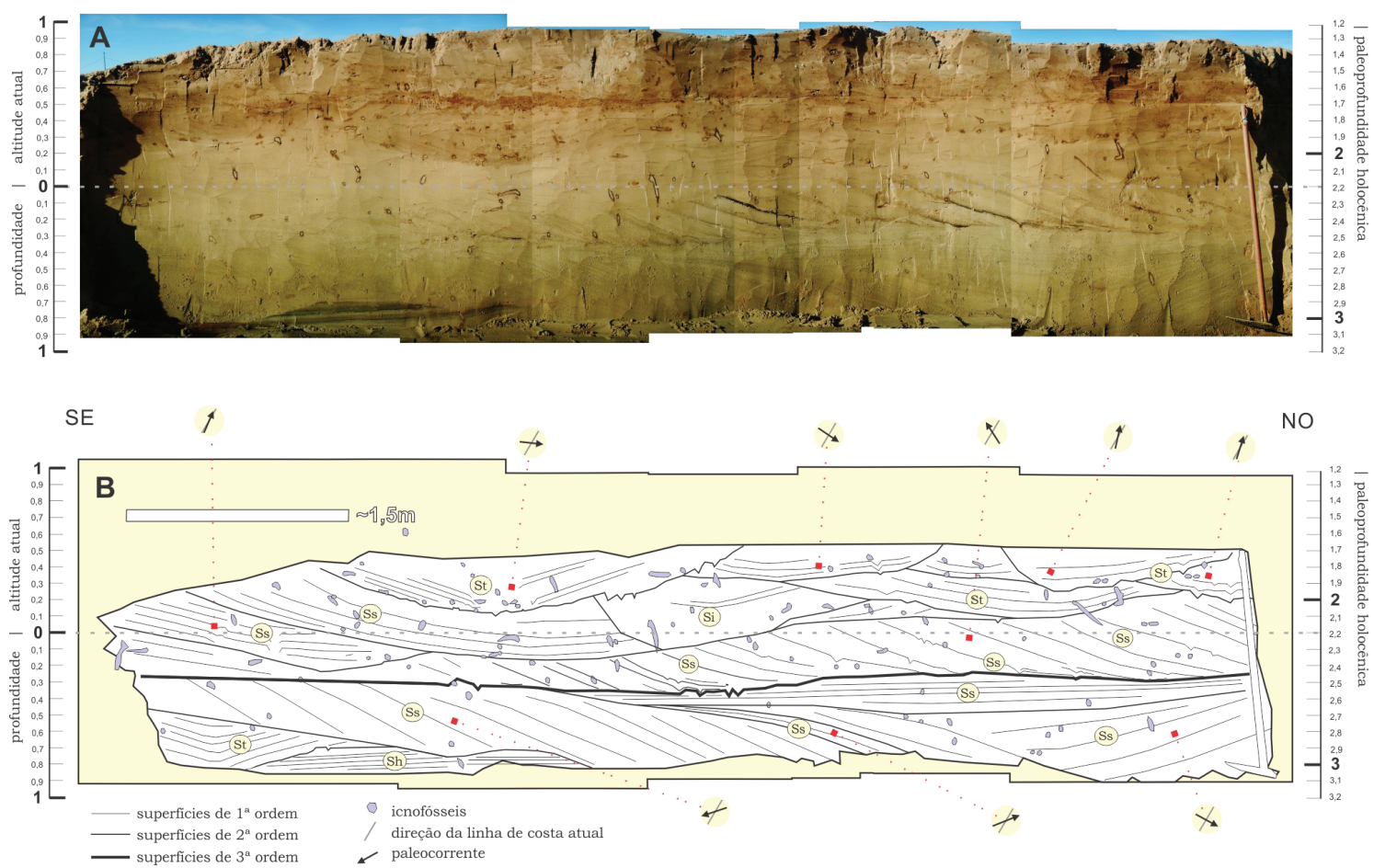

Figura 21. Seção 3 (A) e seu fotomosaico com descrição (B). Areia com estratificação cruzada acanalada (St); Areia com estratificação plano paralela (Sh); Areia com estratificação cruzada sigmoide (Ss).

Figure 21. Section $3(A)$ and its photomontage with description (B). Trough cross-stratified sand (St); Parallel laminated sand (Sh); Sigmoidal cross-stratified sand (Ss). 

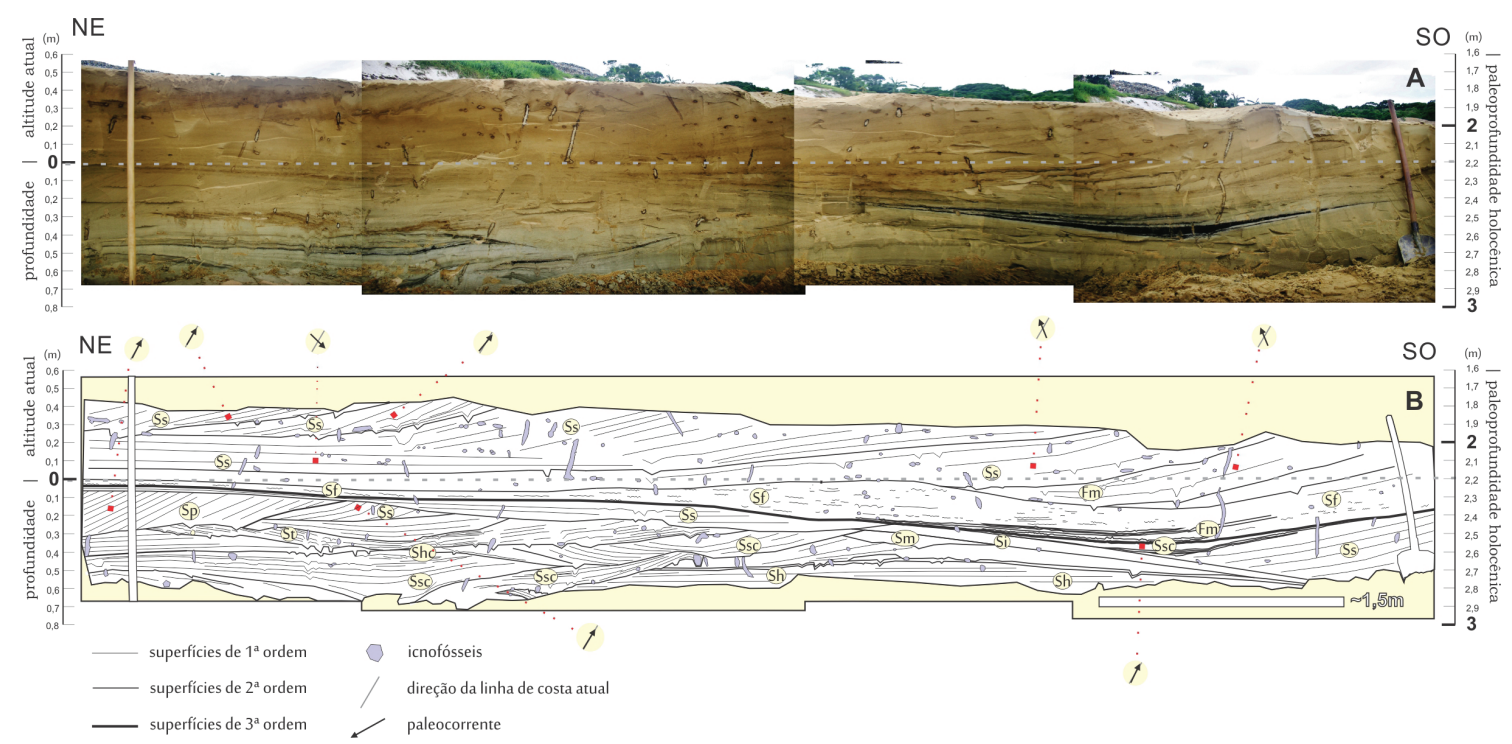

Figura 22. Seção 4 (A) e seu fotomosaico com descrição (B). Areia com estratificação cruzada plana (Sp); Areia com estratificação cruzada acanalada (St); Areia com estratificação cruzada swaley (Ssc); Areia com estratificação plano paralela (Sh); Areia com estratificação cruzada sigmoide (Ss); Areia com estratificação flaser (Sf) e Areia com estratificação cruzada hummocky (Shc).

Figure 22. Section 4 (A) and its photomontage with description (B). Planar cross-stratified sand (Sp); Trough crossstratified sand (St); Swaley cross-stratified sand (Ssc); Parallel laminated sand (Sh); Sigmoidal cross-stratified sand (Ss); Flaser sand (Sf); Hummocky cross-stratified sand (Shc).
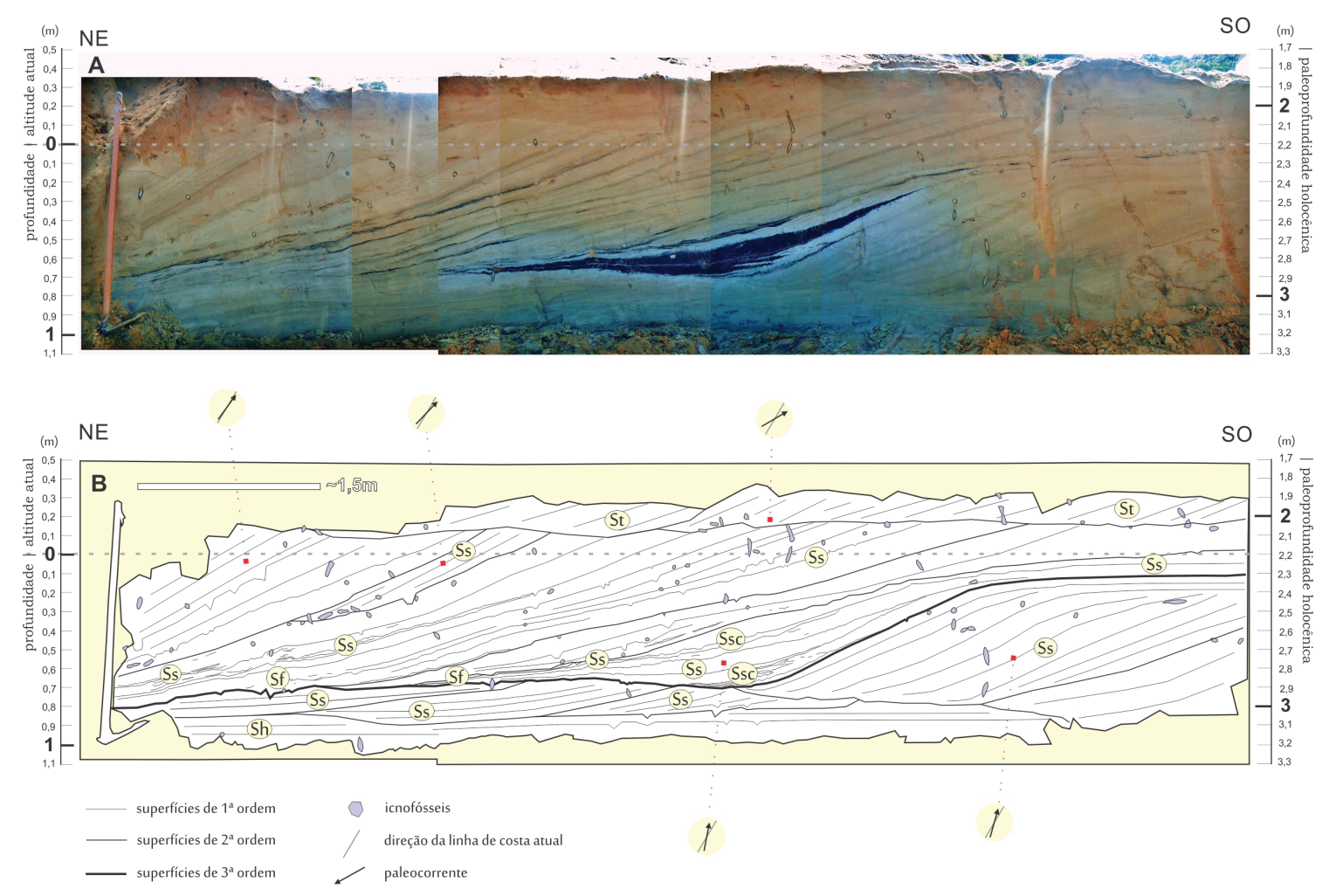

Figura 23. Seção 5 (A) e seu fotomosaico com descrição (B). Areia com estratificação cruzada acanalada (St); Areia com estratificação plano paralela (Sh); Areia com estratificação cruzada sigmoide (Ss); Areia com estratificação cruzada swaley (Ssc); Areia com estratificação flaser (Sf).

Figure 23. Section $5(A)$ and its photomontage with description (B). Trough cross-stratified sand (St); Parallel laminated sand (Sh); Sigmoidal cross-stratified sand (Ss); Swaley cross-stratified sand (Ssc); Flaser sand (Sf). 
subambientes e na arquitetura do depósito (e.g. Morales et al., 2001; Hein et al., 2016).Assim, para o depósito estudado, sugere-se que as estruturas do tipo swaley, hummochy e os drapes de lama foram depositados sob as barras submersas, ou barras de margem de canal, que posteriormente saíram da ação direta de ondas e correntes decorrentes de tempestades, de modo que os depósitos pudessem ser preservados

De acordo com Souza (2005), em datações realizadas para a mesma porção da barreira, os detritos vegetais observados nestas estruturas (Fig. 24) foram depositados centenas a milhares de anos após a morte dos vegetais que lhes deram origem. Estes foram transportados por correntes de maré vazante através dos complexos estuarinos de Paranaguá e Guaratuba, do continente para a plataforma interna, quando o mar possuía níveis semelhantes ou superiores ao atual, entre 8.000 e 5.000 anos A.P (Souza, 2005; Souza et al., 2012). Tais detritos continuaram na plataforma interna, além do limite de ação de ondas de tempestade (durante o período de nível de mar alto) e com a descida progressiva do nível do mar começaram a ser retrabalhados por ondas de tempestade e carreados em direção ao continente, até atingirem a face litorânea inferior e média (Souza, 2005; Souza et al., 2012).

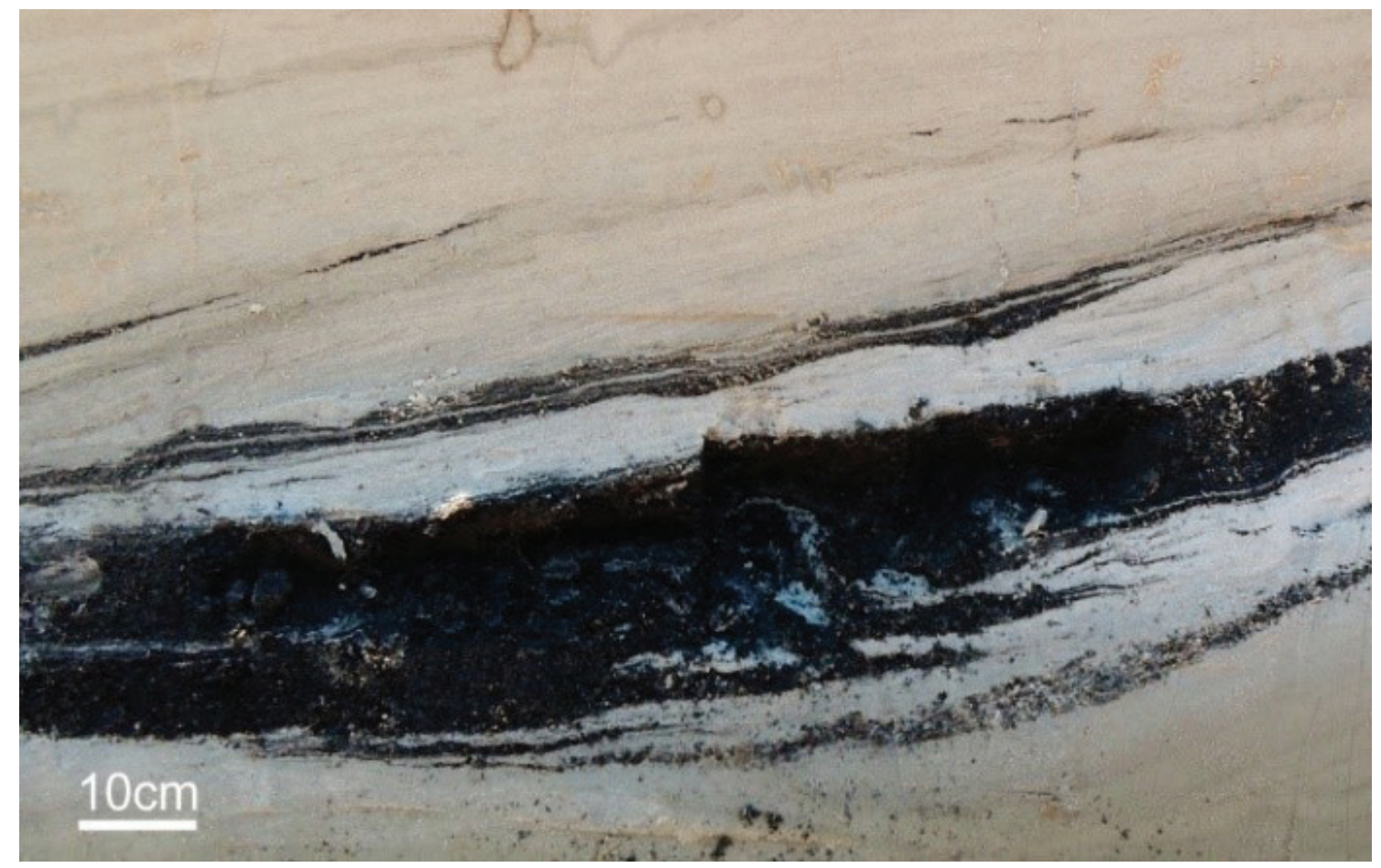

Figura 24. Detalhe de matéria orgânica particulada em (Ssc) da Seção 4. Figure 24. Detail of particulate organic matter in (Ssc) from section 4.

\subsection{Superfícies de descontinuidade nos perfis e ao longo da barreira}

Na Seção 3 (Fig. 21B) há uma visão lateral da estrutura sigmoide descrita da Seção 5 (Fig. 23B) e, devido a sua menor espessura quando comparada à mesma vista da Seção 5, é possível aferir que a estrutura é pontual na barreira, ou ao menos não possui ampla continuidade lateral. Ao observar os fotomosaicos realizados por Bisi (2015) ao longo da barreira, observa-se que este padrão dessimétrico de geometria lenticular com presença abundante de matéria orgânica se repete nos afloramentos paralelos à linha de costa (Fig. 25B, destaque com linha contínua de cor laranja, na parte inferior); e aproximadamente na mesma profundidade, ao observarmos o fotomosaico perpendicular à linha de costa (Fig. 25A, destaque com linha contínua de cor laranja, na parte inferior), nota-se um padrão de superfícies migrando em rumo aparente ao continente (SE). Uma vez que estes padrões de 
superfícies são observados repetidamente ao longo dos fotomosaicos da barreira, sugerese que os depósitos relacionados a eles, as estruturas do tipo swaleys (Ssc) depositadas sob barras nos deltas de maré vazante, possam se tratar de um elemento arquitetônico da barreira, os quais são oriundos de eventos episódicos como a passagem de frentes frias e tempestades, posteriormente preservados.

Ainda sobre a análise dos fotomosaicos realizados por Bisi (2015), observa-se, nos fotomosaicos perpendicular e paralelo a linha de costa, padrões de grandes superfícies planoparalelas no topo da barreira (Fig. 25A e 25B, destaque com linha pontilhada de cor verde, na parte superior). Estes padrões podem estar relacionados aos depósitos de face praial (SI) e de barras de arrebentação (SI(b)) descritos na Seção 1 e Seção 2 (Fig. 19A e 20B) e, uma vez que a repetição destes também é observada ao longo dos fotomosaicos, sugere-se que também possam se tratar de elementos arquitetônicos da barreira.

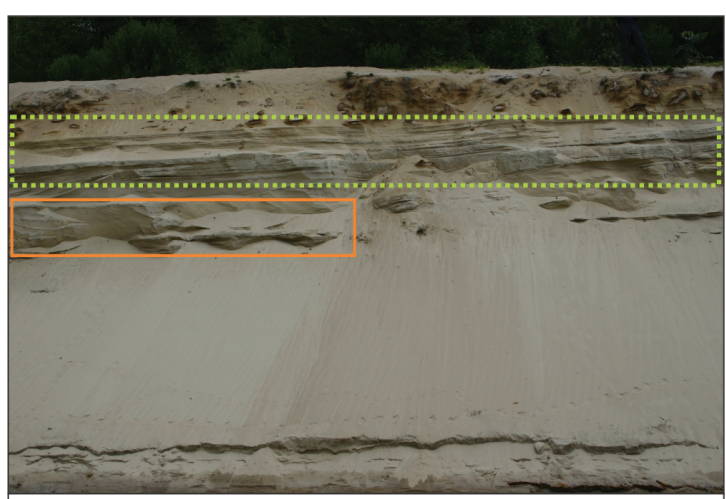

A Perfil perpendicular à linha de costa

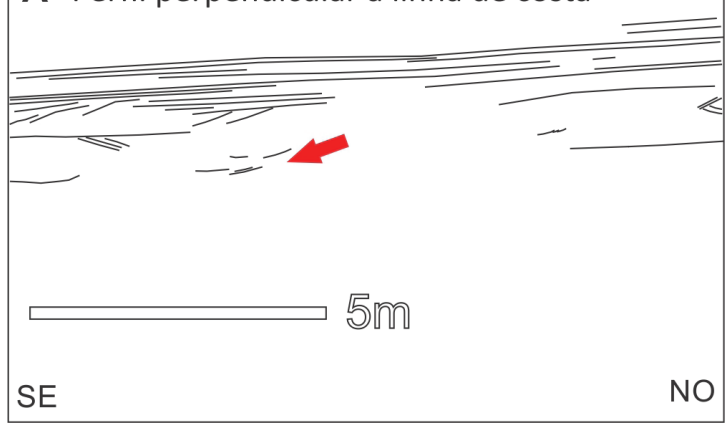

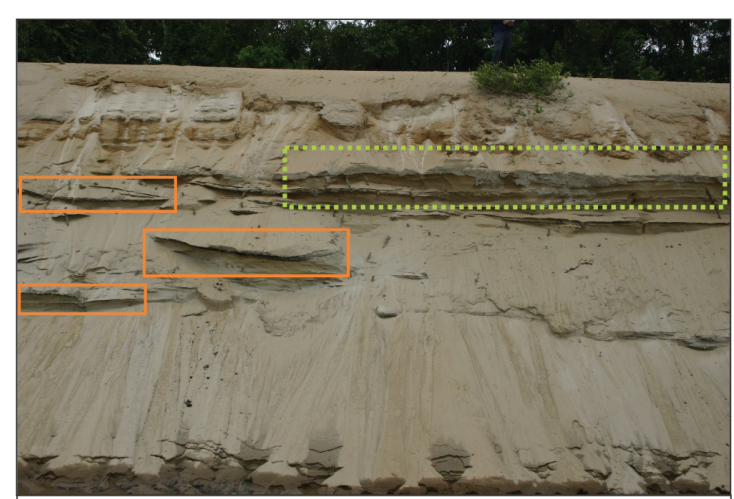

B Perfil paralelo à linha de costa

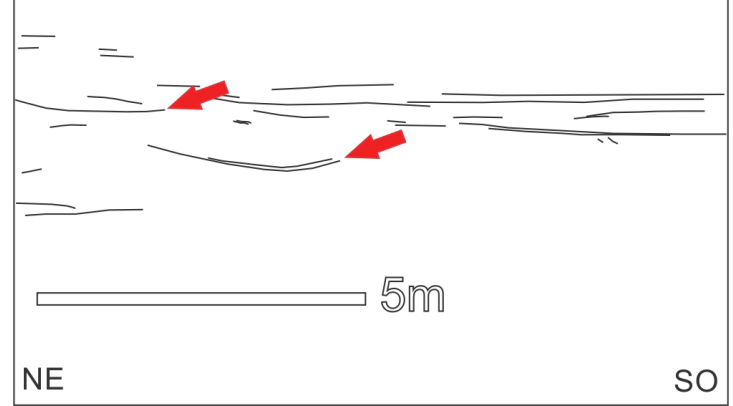

Figura 25. Detalhes de fotomosaicos da barreira e abaixo sua fotointerpretação. A) detalhe do afloramento paralelo à linha de costa, seta destaca as superfícies migrando rumo a SE; B) detalhe do afloramento perpendicular à linha de costa, setas destacam as superfícies swaleys. Modificado de Bisi (2015).

Figure 25. Details of photomontages of the barrier and below its photointerpretation. A) detail of the outcrop parallel to the coastline; B) detail of the outcrop perpendicular to the coastline. Modified by Bisi (2015).

\section{Conclusões}

O presente trabalho, desenvolvido em um trecho da barreira regressiva holocênica paranaense, teve como objetivo identificar as relações laterais de fácies e associações de fácies sedimentares e correlacioná-las com as superfícies de descontinuidade e o seus processos e formas de deposição. A descrição e análise de cinco seções geológicas, juntamente a fotomosaicos obtidos em extensos trechos e dados topográficos, permitiram a identificação de 13 fácies sedimentares distribuídas em três associações de fácies e a hierarquização do depósito em três ordens de superfícies de descontinuidade.

As superfícies de maior ordem $\left(3^{a}\right)$ forneceram informações relevantes acerca dos ambientes de deposição como, por exemplo, a importância dos eventos episódicos de alta energia associados à passagem de frentes frias e tempestades para a construção da barreira holocênica paranaense. A preservação destes depósitos em ambientes mais rasos, quando 
comparado à literatura existente, levantou a hipótese da formação dos mesmos emambientes de deltas de maré vazante. Entretanto, uma investigação mais detalhada deve ser realizada com o intuito de estimar a datação do mesmo e analisar sua continuidade lateral em seções mais extensas, mesmo que por meio indireto como o radar de solo (GPR).

Ainda em relação aos resultados das superfícies de $3^{a}$ ordem obtidos, estes apontam a possível ocorrência de alguns elementos arquitetônicos básicos da barreira, os quais foram denominados como: depósitos de face praial, de barras de arrebentação e de delta de maré vazante, relacionados às superfícies presentes nas associações Praia subaérea-intermaré (PSI), Face litorânea superior (FLS) e Face litorânea média (FLM), respectivamente.

Agradecimentos. Ao Conselho Nacional de Desenvolvimento Científico e Tecnológico (CNPq) pelo apoio financeiro através do projeto número 471039/2013-6 e à Coordenação de Aperfeiçoamento de Pessoal de Nível Superior (CAPES) pela concessão da bolsa de estudo durante a pós-graduação. RJA e MCS agradecem ao CNPq pelas bolsas de produtividade em pesquisa (303940/2014-0 e 305691/2014-7) e RJA agradece à Fundação Araucária pela bolsa Sênior (45725).

\section{Referências bibliográficas}

Angulo, R.J. 1992. Geologia da planície costeira do Estado do Paraná. São Paulo. Tese de Doutorado. Programa de Pós-graduação em Geologia Sedimentar, Instituto de Geociências, Universidade de São Paulo.

Angulo, R.J. 1993. A ocupação urbana do litoral paranaense e as variações da linha de costa. Boletim Paranaense de Geociências, 41: 7381.

Angulo, R.J. 1999. Morphological characterization of the tidal deltas on the coast of the State of Paraná. Anais da Academia Brasileira de Ciências, 71(4-II): 935-959.

Angulo, R.J. 2004. Mapa do Cenozóico do litoral do Estado do Paraná. Boletim Paranaense de Geociências, 55: 25-42.
Angulo, R.J. \& Araújo, A.D. 1996. Classificação da costa paranaense com base na sua dinâmica como subsídio à ocupação da orla litorânea. Boletim Paranaense de Geociências, 44: 7-17. Angulo, R.J. \& Lessa, G.C. 1997. The Brazilian sea level curves: a critical review with emphasis on the curves from Paranaguá and Cananéia regions. Marine Geology, 140: 141-166.

Angulo, R.J., Lessa, G.C. \& Souza, M.C. 2006. A Critical Review of Mid- to Late Holocene Sealevel Fluctuations on the Eastern Brazilian Coastline. Quaternary Science Reviews, 25: 486-506.

Angulo, R.J., Lessa, G.C. \& Souza, M.C. 2009. The Holocene barrier systems of Paranaguá and northern Santa Catarina coasts, southern Brazil. In: Dillenburg, S.R \& Hesp, P.A (Orgs.). Geology and Geomorphology of Holocene Coastal Barriers of Brazil. Berlin, SpringerVerlag, p. 135-176.

Bisi, F.N. 2015. Arquitetura deposicional da barreira regressiva holocênica de Praia de Leste, Paraná. Curitiba, 41-74p. Dissertação de Mestrado, Programa de Pós-Graduação em Geologia, Universidade Federal do Paraná. Dalrymple, W.R. 2010. Interpreting sedimentary successions: Facies, Facies Analysis and Facies Models. In: James, N.P. \& Dalrymple. R.W. (Ed.). Facies Models 4. Canada, Department of Geological Sciences and Geological Engineering Queen's University, p. 3-18.

Hansen, J.E., Elias, E., Barnard, P. L. 2013. Changes in surfzone morphodynamics driven by multidecadal contraction of a large ebb-tidal delta. Marine Geology, 345: 221-234.

Harrison, S.R., Bryan, K.R. \& Mullarney, J.C. 2017. Observations of morphological change at an ebb-tidal delta. Marine Geology, 385: 131-145. Hein, C.J., Fitzsimons, G.G., FitzGerald, D.M. \& Fallon, A.R. 2016. Records of Migration and Ebb-Delta Breaching at Historic and Ancient Tidal Inlets along a River-Fed Paraglacial Barrier Island. Journal of Coastal Research, 75: 228-232.

Hughes, M. \& Turner, I. 1999. The Surf Zone. In: Short, A.D (Ed.). Handbook of Beach and Shoreface Morphodynamics. London, John Wiley, p. 119-169. 
Jia, L., Wen, Y., Pan, S., Liu, J.T. \& He, J. 2015. Wave-current interaction in a river and wave dominant estuary: A seasonal contrast. Applied Ocean Research, 52: 151-166.

Lessa, G.C., Angulo, R.J., Giannini, P.C.F. \& Araújo, A.D. 2000. Stratigraphy and Holocene evolution of a regressive barrier in south Brazil. Marine Geology, 165(1-4): 87-108.

Marone, E. \& Camargo, R. 1995. Efeitos da maré meteorológica na baía de Paranaguá, PR. Nerítica, 8: 71-81.

Marone, E., Mantovanelli, A., Klingenfuss, M. S., Lautert, L.F.C. \& Prata, Jr V.P. 1997. Transporte de Água, Sal, Material Particulado em Suspensão e Calor na Gamboa do Perequê num Evento de Maré de Sizígia. In: CONGRESSO LATINO-AMERICANO DE CIÊNCIAS DO MAR, 7., Santos, Brasil. Anais...Santos, COLACMAR, v. 2. p. 134-136.

Martin, L., Suguio, K., Flexor, J.M., Azevedo, A.E.G. 1988. Mapa geológico do Quaternário costeiro dos Estados do Paraná e Santa Catarina. Brasília, Departamento Nacional de Produção Mineral. Série Geologia 28, Seção Geologia Básica 18, 40p.

Miall, A.D. 1978. Lithofacies types and vertical profile models in braided river deposits: a summary. In: Miall, A.D. (Ed.). Fluvial Sedimentology. Mem. Canadian Society of Petroleum Geologists. v. 5. p. 597-604.

Miall, A.D. 1985. Architectural-element analysis: a new method of facies analysis applied to fluvial deposits. Earth-Science Reviews, 22: 261-308.

Miall, A.D. 1988. Reservoir heterogeneities in fluvial sandstones: lessons from outcrop studies. American Association Petroleum Geologists Bulletin, 72(6): 682-697.

Miall, A.D. 1996. The Geology of Fluvial Deposits. Berlin. Springer-Verlag, p. 582.

Morales, J.A., Borrego, J., Jiménez, I., Monterde, J. \& Gil, N. 2001. Morphostratigraphy of an ebbtidal delta system associated with a large spit in the Piedras Estuary mouth (Huelva Coast, Southwestern Spain). Marine Geology, 172: 225-241.
Pianca, C., Mazzini, P.L.F. \& Siegle, E. 2010. Brazilian offshore wave climate based on NWW3 reanalysis. Brazilian Journal of Oceanography, 58(1): 53-70.

Plint, A.G. 2010. Wave and storm-domitated shoreline and shallow-marine systems. In: James, N. P \& Dalrymple, R. W. (Ed.), Facies Models 4. Department of Geological Sciences and Geological Engineering Queen's University, p. 167-199.

Quadros, C.J.L. 2002. Variações morfológicas e volumétricas associadas à incidência de sistemas frontais em duas praias arenosas do litoral paranaense. Curitiba, 57p. Dissertação de Mestrado. Programa de Pós-Graduação em Geologia, Universidade Federal do Paraná. Quadros, C.J.L., Marone, E., Angulo, R.J., Martins, G.J. \& Netto Jr., J.P.B. 2007. Dinâmica morfosedimentar associada à incidência de sistemas frontais em duas praias do litoral paranaense. Boletim Paranaense de Geociências, 60-61: 65-74.

Short, A.D. 1999. Handbook of Beach and Shoreface Morphodynamics. Chichester, John Wiley \& Sons. 379p.

Souza, M.C. 2005. Estratigrafia e evolução das barreiras holocênicas paranaenses, Sul do Brasil. Curitiba. Tese de Doutorado, Programa de Pós-graduação em Geologia, Universidade Federal do Paraná.

Souza, M.C., Angulo, R.J., Assine, M.L. \& Castro, D.L. 2012. Sequence of facies at a Holocene storm-dominated regressive barrier at Praia de Leste, southern Brazil. Marine Geology, 291-294: 49-62.

Spydell, M.S., Feddersen, F., Olabarrieta, M., Chen, J., Guza, R.T., Raubenheimer, B. \& Elgar, S. 2015. Observed and modeled drifters at a tidal inlet. Journal of Geophysical Research: Oceans, 120: 4825-4844.

Walker, R.G. 1992. Facies, facies models and modern stratigraphic concepts. In: Walker, R. G. \& James, N. P. (Ed.). Facies models: response to sea level change. St. John's, Geological Association of Canada, p. 1-14. 